\title{
DOI 10.1590/1807-01912014202219 Padrões distintos de bem-estar no Brasil: uma análise temporal
}

\author{
\begin{tabular}{c}
\hline \hline Natália Guimarães Duarte Sátyro \\
Departamento de Ciência Política \\
Universidade Federal de Minas Gerais \\
\hline \hline
\end{tabular}
}

\begin{abstract}
Resumo: 0 objetivo do artigo é mostrar a existência de diferentes mundos de bem-estar no Brasil. Sugerimos aqui tanto a existência de distintos mundos de bem-estar entre os estados brasileiros quanto uma mudança fundamental em nosso sistema de proteção social no período posterior à Constituição de 1988. A conclusão é que a discrepância entre os mundos de bem-estar encontrados nos estados nos permite dizer que no Brasil há categorias distintas de cidadãos, com acessos diferenciados a serviços básicos. Os estados apresentam distintos legados e, portanto, distintas trajetórias nas três décadas analisadas, mas há uma tendência à convergência nesse bem-estar. Essa heterogeneidade se traduz em padrões distintos de segurança social. Para isso, a metodologia utilizada foi basicamente análise descritiva através de séries temporais e análise de conglomerado.
\end{abstract}

Palavras-chave: Estado de bem-estar; políticas sociais; estados brasileiros; análise de cluster

Abstract: The objective of this paper is to show the existence of different worlds of welfare in Brazil. We suggest that as the existence of distinct worlds of welfare across Brazilian states as a fundamental change in welfare after the 1988 Constitution. The conclusion is the discrepancy between the worlds of welfare found between states allows us to say that in Brazil there are distinct categories of citizens, with differentiated access to basic services. We also show that states have different legacies and therefore different trajectories in the three decades analyzed, but there is a trend towards convergence in welfare. This heterogeneity is reflected in distinct patterns of social welfare. For this, the methodology used was basically a descriptive analysis based in time series and cluster analyses.

Keywords: welfare state; social policies; Brazilian states; cluster analysis 


\section{OPINIÃO PÚBLICA, Campinas, vol. 20, n 2, agosto, 2014, p.219-251}

\section{Introdução}

A comparação institucional constitui um desenho analítico interessante para estudar regimes de bem-estar social. É assim que tem sido produzido boa parte do conhecimento sobre os Estados de bem. estar social (EBES) desde a década de $1980^{1}$ (ESPING-ANDERSEN, 1999). A forma da intervenção estatal para lidar com as questões conflitivas por meio de proteção social no Brasil nas primeiras décadas do século XX e as características marcantes do nosso sistema de proteção que predominaram até os anos 1980 produziram uma sociedade estratificada nos termos esping-anderseanos (ESPING-ANDERSEN, 1990; 1999). O Estado de bem-estar social aqui implantado teve consequências diretas para a formação de capital humano e para a distribuição de renda no país mas, a partir da Constituição de 1988 (CF.88), há alterações substantivas nesse modelo (SÁTYRo e CUNHA, 2014; SÁTYRO, 2010; CASTRO e CARDOSO, 2005; IPEA, 2009). Muitas mudanças ali introduzidas foram determinantes para a inauguração de uma nova era no sistema de proteção nacional na medida em que foi incluída solidariedade nacional no sistema e aumentou substantivamente a capacidade inclusiva do mesmo modificando seu caráter dual: dos que têm proteção e dos não segurados. Mesmo assim, embora as diretrizes constitucionais tenham sido nacionais, vivenciamos acessos distintos de bem-estar social entre os estados brasileiros; há aqui mundos de bem-estar social diferenciados resultado, entre outros fatores, tanto do legado de proteção social quanto das características do mercado de trabalho que determinaram a conformação de uma heterogeneidade de bem-estar acessado nos diferentes estados.

Este artigo, de natureza descritiva, faz uma comparação entre os mundos de bem-estar social nos estados brasileiros, numa perspectiva longitudinal e comparativa, a partir do início da década de 1980. Observamos uma convergência entre os estados a partir de meados dos anos 1990 que, entre outros fatores, acreditamos ter sido influenciada por dois fatores importantes: os processos institucionais de implementação de diretrizes e mudanças paradigmáticas trazidas pela CF.88 e também a recuperação da economia e do fim da crise vivida na década de 1980 . O objetivo do artigo é mostrar tanto a estratificação social pela existência de mundos de bem-estar entre os estados brasileiros, quanto a diferença entre o momento anterior e o posterior à CF.88.

A maior parte da literatura que trabalha com regimes ou Estados de bem-estar social utiliza gastos sociais como indicador de provisão social. Este artigo procura uma estratégia distinta. A pretensão é utilizar indicadores de condições socioeconômicas e de mercado de trabalho, isto é de bem. estar geral e setorial numa perspectiva que os considera como a consequência do que ali se tem produzido de políticas sociais. Se essa é uma premissa frágil para análises cross-section, não o é para um painel como o presente estudo onde os efeitos poderão ser captados no tempo. Assim, consideramos aqui os resultados como indicadores dos investimentos sociais naquela área no período $t$ - 1 . Para nós não está posta a discussão de qual âmbito governamental numa federação como a brasileira é responsável por tais resultados. Temos aqui a intenção de ressaltar as consequências da ação do poder público, do Estado mais enfaticamente, mesmo reconhecendo a importância de outros atores, em menor ou maior escala, na promoção de bem-estar social. Ou seja, não haverá a consideração se a maior

\footnotetext{
1 Em Social Foundations, Esping-Andersen (1999) revê a utilização do conceito de regime de estados de bem-estar social e passa a utilizar o constructo regimes de bem-estar social que incorpora a ação de outras instituições para além do Estado na provisão de bem-estar social, mais especificamente mercado e família. Como o objetivo deste artigo visa mensurar o papel do Estado nessa provisão, adotaremos o conceito de Estado de bem-estar apesar de concordar com a revisão do autor.
} 


\section{SÁTYRO, N. G. D. Padrões distintos de bem-estar no Brasil: uma análise temporal}

responsabilidade de uma área é do poder municipal, do estadual ou do federal, mas sim que, em seu conjunto, essa ação produz resultados que levam a acessos diferenciados aos direitos sociais.

A conclusão do artigo é que a discrepância entre os mundos de bem-estar encontrados nos estados nos permite dizer que no Brasil há distintas categorias de cidadãos com acessos diferenciados a serviços básicos e, portanto, a direitos sociais. As distâncias entre esses mundos mostraram uma tendência de queda a partir dos anos 1990, mas estas se intensificaram somente nos anos 2000. Isso sugere que houve mudanças substantivas que reconfiguraram o sistema de proteção social brasileiro após a CF-88, mas algo distinto na política ocorreu no início do século XXI.

Para alcançar seu objetivo o artigo está organizado em três seções: uma breve apresentação do marco analítico que nos mostra a importância da ideia de legado enquanto resultado de escolhas de políticas prévias impactando na conformação das políticas atuais e nos resultados alcançados e alcançáveis; uma segunda parte em que mostramos a existência dos diferentes mundos de bem-estar social e, por fim, as considerações finais.

\section{O legado e o papel das regras do jogo}

Há dois fatores dentro da abordagem neo-institucionalista que interessam para o argumento aqui construído: o legado e a importância das regras do jogo. Este artigo comunga com as conclusões de Immergut (1992) que sugere que as normas constitucionais estabeleceram limites à capacidade dos governos para fazer reformas. Os atores interessados utilizaram-se das barreiras legais para pautar a suas ações. Ou seja, as regras constitucionais e o desenho das instituições políticas com suas regras determinam os resultados diferenciados em políticas públicas. Assim, podemos afirmar que uma vez (re)definidas as regras do jogo isso impactará diretamente na ação dos atores políticos e na conformação das políticas elaboradas pelos governos na medida em que constrange a ação dos mesmos. Aqui ressaltamos a importância das mudanças trazidas pela arena constitutiva, ou seja, as mudanças nas regras do jogo dadas pela CF-88. As escolhas feitas pelos constituintes nacionais transformaram a cara do regime de proteção social promovendo mudanças significativas, mas as consequências das escolhas feitas anteriormente são fortes o suficiente para manter as distâncias relativas entre os estados.

Dentro dessa perspectiva institucional e política, uma dimensão importante para o desenvolvimento do presente artigo é a força das políticas prévias por seu caráter de escolhas políticas que foram feitas anteriormente criando constrangimento na ação (SKOCPOL, 1992). Pierson (2001) afirma que o legado deve ser visto como tendo estruturas consequenciais. A base para esse argumento é o conceito de rota dependente (path dependency) que nos coloca que os contornos institucionais em um momento no tempo passado criam constrangimentos reais para o contorno atual, ou dizendo de outra forma o que aconteceu no passado condiciona o que acontece no presente. De acordo com Douglas North, tanto os contornos institucionais quanto as construções internalizadas pelos atores envolvidos no processo político devem ser entendidos enquanto categorias analíticas internas ao conceito; o que Pierson mais tarde vai falar de efeitos de aprendizagem dos atores no processo decisório como sendo efeitos de políticas prévias (NORTH, 1995; PIERSON, 2001). No nosso caso devemos pensar que quando uma nação, estado ou município adota a política do não investimento em capital humano, por meio da não oferta de serviços básicos, em saúde e educação, por exemplo, os custos e o tempo de reversão das consequências disso podem ser altos e demorados. Todavia, Souza (2003) reforça que o interessante 
desse conceito é que ele também comporta mudança, é possível esperar ações que combatam a rota anterior por meio de políticas que permitam mudança de direção (Souza (2003) cita Pierson, 2000, p.252). Ou seja, a análise com base nesse conceito comporta a ideia de mudança mesmo com uma rota dependente muito forte.

\section{O legado de proteção}

Para os fins deste artigo é de grande utilidade a periodização e a caracterização do EBES brasileiro realizado por Aureliano e Draibe (AuRELIANO e DraIBE, 1989; DRAIBE, 2003; 2005). As características do padrão de intervenção do estado brasileiro levam Aureliano e Draibe a caracterizarem o nosso regime de bem-estar como um welfare state meritocrático-particularista, baseado na tipologia de Titmuss $^{2}$. Ou seja, não há dúvidas de que o nosso modelo, na maior parte de sua história, se aproxima do modelo conservador - corporativo esping-andersiano (ESPING-ANDERSEN, 1990; 1999) fundado na capacidade contributiva e, portanto, discriminatório pelo tipo de inserção do indivíduo no mercado de trabalho e respaldado pelo princípio do mérito "entendido basicamente como a posição ocupacional e de renda adquirida ao nível da estrutura produtiva" e não pelo seu status de cidadão (DRAIBE, 1993, p.23).

Esse modelo estratificou a sociedade dualmente entre os que têm proteção e os que não têm. $E$ dentro daqueles que acessavam os direitos securitários surgiram tantos estratos quanto o número de categorias profissionais reconhecidas. Mudança nesse padrão se deu na década de 1970 com a incorporação de várias categorias antes desprotegidas, mas isso foi feito com uma diminuição no valor real dos benefícios. Dessa forma, a autora reafirma que a grande clientela e a sua rápida expansão principalmente na década de 1970 aumentarem as distorções no welfare state brasileiro. E o fato de que as políticas sociais universais existentes não eram, nem de longe, suficientes para reduzir desigualdades foi apontado como um dos muitos pontos problemáticos até a década de 1980 (DRAIBE, 2005). Com esse desenho temos o seguinte cenário: a Saúde era securitária, portanto, só uma parcela da população tinha acesso a serviços de assistência médica fortemente concentrada nos grandes centros urbanos; a Assistência Social não era reconhecida como política, o que dificultava a incorporação de grupos em situações mais vulneráveis. E, por fim, a Educação tinha um alcance muito reduzido produzindo uma heterogeneidade educacional perversa que determinava diferentes níveis salariais (SÁTYRO, 2013).

Mesmo com as mudanças paradigmáticas trazidas pela CF.88, carregamos um legado de décadas de um modelo securitário, meritocrático e corporativo numa sociedade sem pleno emprego que consolidou em nosso meio uma cidadania regulada (SANTOS, 1979), contribuindo para a construção de diferentes mundos de bem-estar. Nos termos de Esping.Andersen, o EBES implantado desde 1930 gerou uma sociedade estratificada, uma sociedade de cidadãos que acessavam diferentes conjuntos de direitos sociais. A história brasileira de proteção social resultou em acentuadas diferenças no capital humano (heterogeneidade educacional + heterogeneidade de saúde) este, por sua vez, determinante para a manutenção de níveis muito diferenciados de inserção no mercado de trabalho e, portanto, para a manutenção de altos índices de desigualdade de renda (FERREIRA, 2000, BARROS et al, 2007).

\footnotetext{
2 Infelizmente, o texto foi publicado um ano antes da publicação do the three worlds (1990) e as autoras não puderam se beneficiar das reflexões trazidas por Esping-Andersen.
} 


\section{SÁTYRO, N. G. D. Padrões distintos de bem-estar no Brasil: uma análise temporal}

$O$ legado do mercado de trabalho

O período aqui analisado permite-nos falar também de um legado econômico de (des)estruturação do mercado de trabalho, fruto da crise econômica vivida na década de 1980 até meados da década de 1990. Falamos aqui, por um lado, da perda em grandes proporções de postos formais no setor industrial, paralela à precarização dos postos de trabalho junto com crise e estagnação da economia e, por outro lado, do empobrecimento da população em geral. Segundo Dedecca, "a crise dos anos 1980 provocou uma queda aproximada de 25\% na Produção Industrial acompanhada por uma redução semelhante do nível de emprego industrial" com o desemprego chegando a mais de $20 \%$ da população economicamente ativa da grande São Paulo (DEDECCA, 2005, p.102). Lembremos que até meados da década de 1980 não havia seguro-desemprego na extensão que se deu depois da CF.88 e como a proteção social era dada pela inserção no mercado o impacto foi grande.

Entretanto, não é o desemprego sozinho a grande vedete, mas a informalização da economia que tem processos diferenciados entre os estados brasileiros (SABÓIA, 1986). Nesse momento, o que se assistiu foi uma reestruturação produtiva com acentuadas transformações na economia nacional que alteraram o padrão de incorporação da força de trabalho (BALTAR, 2000; MONTALI, 2004). Mesmo que a informalidade sempre tenha marcado as relações de trabalho brasileiras, autores como Ibarra (2007) e Montali (2004), entre outros, mostram que entre as principais causas do aumento desse processo na década de 1990 destacam-se a "reestruturação produtiva, os fenômenos de terceirização e terciarização, um aumento da participação das mulheres no mercado de trabalho, além da estagnação do processo migratório para as grandes metrópoles" (IBARRA, 2007, p.1-2). E, de acordo com Ibarra, somente a partir de 2000 é que se observa uma reversão dos graus de informalidade e de crescimento dos empregos formais. Este cenário pode ser visualizado no Gráfico 1: 
Gráfico 1

Grau de Informalidade - Brasil

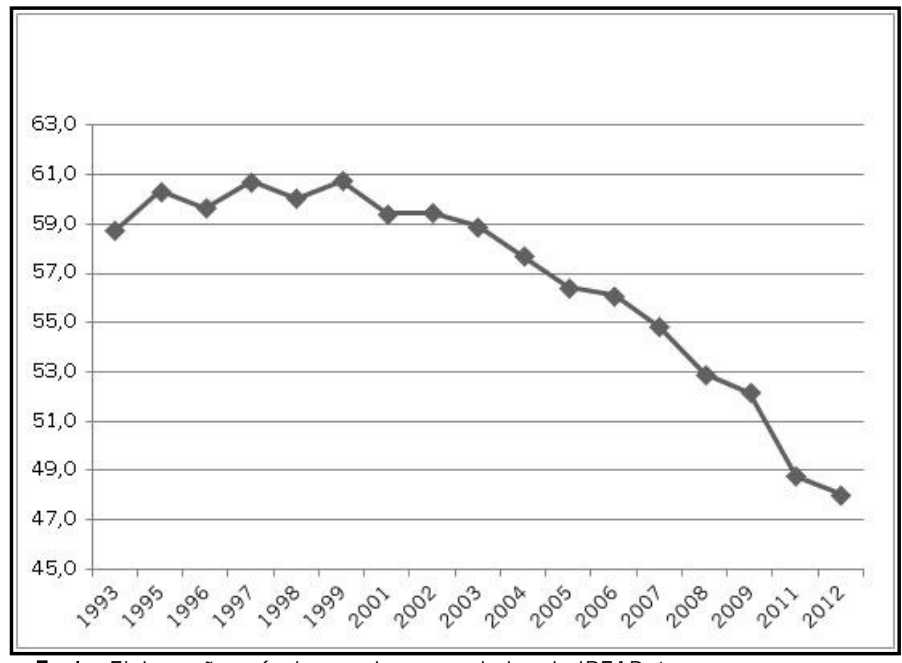

Fonte: Elaboração própria com base em dados do IPEAData.

Baltar (2000), ao analisar a estrutura ocupacional regional nos anos 1990, mostra o que todos já sabemos, que a atividade econômica caracteriza-se pela concentração no sudeste e no sul do país uma vez que, em 1998, "essas duas (regiões) têm em conjunto $61,6 \%$ da população e 79,6\% do PIB enquanto o Nordeste, no outro extremo, possui 30,4\% da população e somente 13,7\% do PIB" (BALTAR, 2000, p.7). Mas, o autor mostra como a reestruturação produtiva da década de 1990 atingiu de forma diferente os estados brasileiros. E, mais interessante ainda para os objetivos do artigo, é sua afirmação de que "as diferenças regionais de renda per capita algo diminuíram, porém muito mais em consequência do seu não aumento no estado de São Paulo do que pelo ímpeto do seu aumento nas demais regiões" (BALTAR, 2000, p.14). Ou seja, não há uma mudança estrutural em vista que permita-nos inferir uma taxa de crescimento mais acelerada nas demais regiões que induziria a uma desconcentração da atividade econômica e consequente aumento da formalização do mercado de trabalho no restante do país. Para o autor, continuávamos a assistir a uma "proliferação de ocupações sem a proteção social do trabalho assalariado regulamentado" com pouco ou nenhuma mudança substantiva no legado da estrutura produtiva. Esse cenário só muda substantivamente a partir de 2003.

Por fim, temos que destacar outra dimensão importante para entender as diferenças encontradas entre os estados em sua heterogeneidade relativa ao acesso ao mercado de trabalho, que são os baixos níveis de educação formal (FISHLOW, 1972). Ferreira (2000) enfatiza o grau de heterogeneidade educacional encontrado como sendo a principal causa da desigualdade de renda. Barros, Corseuil e Leite (2000) mostram que desigualdade de renda tem relação com a alocação de recursos humanos disponíveis para as atividades econômicas. Quanto maior for a subutilização dos recursos humanos nas atividades econômicas, tanto maior será o nível de pobreza. O que estamos querendo aqui é mostrar que, complementarmente ao quadro de estagnação econômica, encontramos no Brasil um nível de heterogeneidade educacional que também tem papel determinante na construção das disparidades regionais tão reafirmada por diversos autores. E isso importa ainda mais quando 


\section{SÁTYRO, N. G. D. Padrões distintos de bem-estar no Brasil: uma análise temporal}

defendemos que a heterogeneidade educacional é resultado de políticas educacionais empreendidas ao longo do tempo (FISHLow, 1972; FERREIRA, 2000), ou seja, da ação ou inação do Estado.

Essas trajetórias constituem o esteio a partir do qual se constituíam institucionalmente as diferentes 'cidadanias' dentro do território nacional e sugerem, a partir da análise aqui realizada, como a rota futura em cada estado depende da trajetória anterior (rota dependente de trajetória) mesmo com mudanças constrangedoras advindas de um formato de proteção social mais inclusivo preconizado pela CF.88.

\section{A existência de dois padrões de bem-estar entre os estados brasileiros}

O objetivo desta seção é mostrar a existência de dois padrões distintos de bem-estar social no Brasil antes e depois da CF.88. Mais que isso, observa-se a existência de diferentes padrões de bemestar entre os estados brasileiros, principalmente, mudança de tendências nestes padrões depois da Constituição com nítido movimento de convergência nos anos 2000. Para isso faremos uma análise longitudinal com corte transversal o que nos permitirá mostrar que quando analisamos as condições de bem-estar da população visualizamos uma disparidade enorme entre os estados no início da série histórica. O quadro se altera substantivamente e há uma convergência entre os estados, mas ainda se mantém uma distância efetiva entre eles uma vez que as distâncias relativas se mantêm na maior parte dos casos. Sempre que possível os dados são analisados com os seguintes recortes: década de 1980 até 1995, de 1995 a 2003 e de 2003 até 2012, o que nos ajuda a considerar na análise períodos de governos distintos no âmbito federal.

\section{A base de dados}

A base de dados usada é formada pelas 27 unidades federativas do Brasil: os 26 estados mais - Distrito Federal. Os dados foram extraídos do IPEAData, banco de dados disponíveis no site do Instituto de Pesquisa Econômica Aplicada (IPEA) e do Departamento de Informática do SUS, o Datasus. A disponibilidade das informações varia para cada indicador indo de 1981 a 2012; dessa forma, não há um painel balanceado, ou seja, as séries não são contínuas. Os dados para Tocantins começam a partir de 1992, três anos depois de sua implantação. O Quadro 1 sintetiza a operacionalização dos indicadores utilizados: 
OPINIÃO PÚBLICA, Campinas, vol. 20, no 2, agosto, 2014, p.219-251

\section{Quadro 1 \\ Indicadores utilizados}

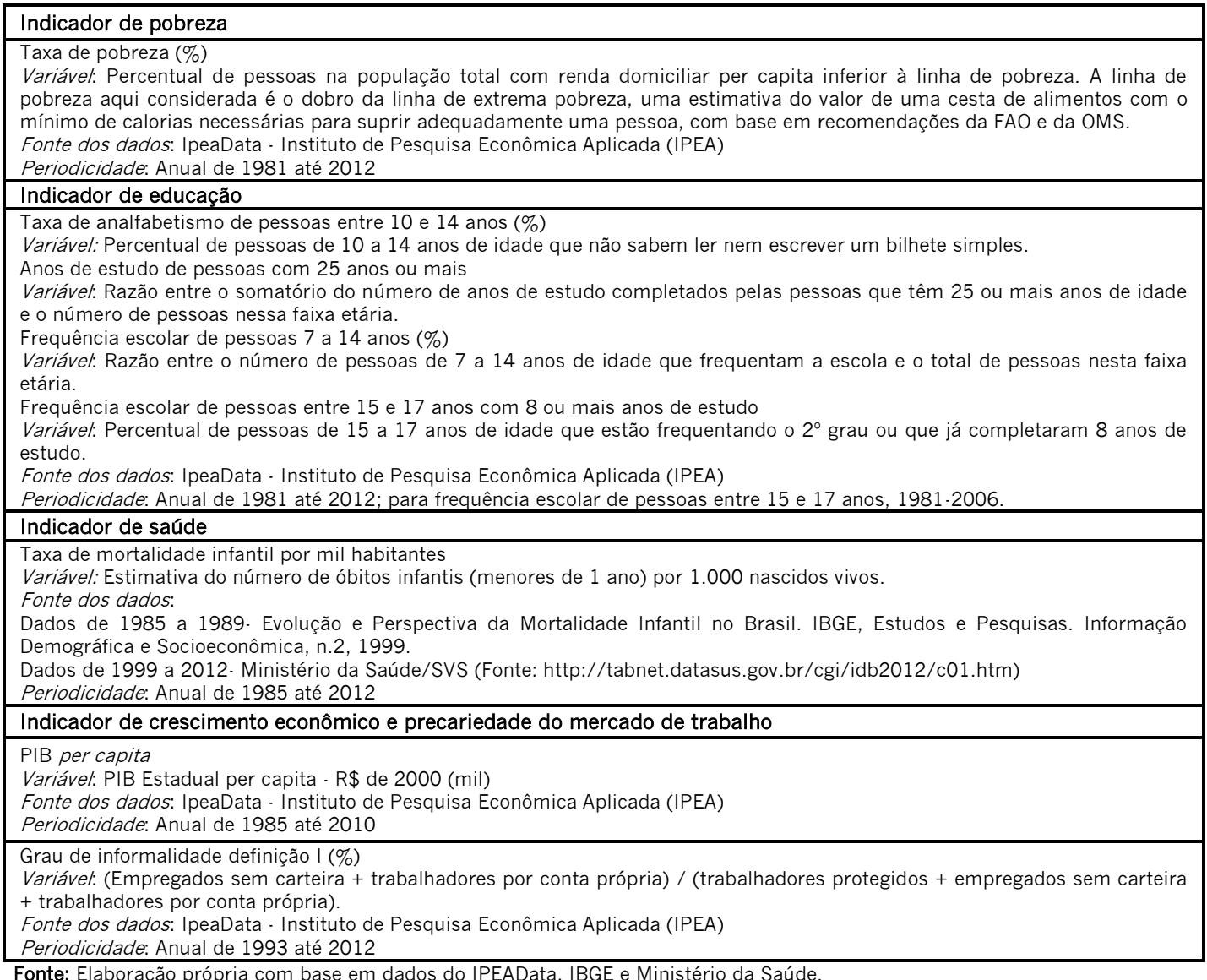

\section{A análise}

São três aspectos que serão enfatizados: a) a dessemelhança no bem-estar social visto em cada um dos indicadores aqui utilizados no conjunto dos estados em todo o período, em especial, na década de 1980; b) as diferentes tendências observadas nos períodos analisados, antes e depois de 1988, sendo que, de forma geral, os indicadores se mostram persistentes na década de 1980 apresentando um ponto de inflexão a partir de meados da década de 1990 e uma melhora mais contundente após 2003; e, c) a manutenção das diferenças relativas mesmo diante da melhora em termos reais.

Para isso foram produzidas tabelas que trazem vários dados. Primeiro, os valores do indicador a ser analisado para os seguintes anos: 1981, 1995, 2003 e 2012 ( $\left.Y_{i} 1981 ; Y_{i} 1995 ; Y_{i} 2003 ; Y_{i} 2012\right)$. Segundo, é apresentado o ranking por ordem crescente do indicador em questão para os anos de $1981 \mathrm{e}$ 2012, respectivamente; e logo após é apresentado o delta do ranking que nada mais é do que a variação de posição daquele estado em relação ao indicador. Terceiro, são apresentadas as taxas de crescimento anual do indicador nos períodos 1981.1995; 1995.2003 e 2003.2012. Esses recortes nos permitem análises que consideram diferenças nas políticas empreendidas no nível nacional e estadual que são 


\section{SÁTYRO, N. G. D. Padrões distintos de bem-estar no Brasil: uma análise temporal}

importantes para levantar hipóteses. Todas as tabelas mostram a relação entre todos os estados em relação ao que apresenta a melhor posição no indicador no início e no fim da série. Por fim, cabe dizer que é impossível no corpo de um artigo desse porte analisar todos os dados de todas as tabelas, o texto ressaltará apenas alguns aspectos

Antes de analisarmos os indicadores por área setorial é conveniente analisarmos as disparidades entre os estados no que se refere ao percentual de pessoas na população total abaixo da linha de pobreza. Esse indicador nos dá a dimensão da população não protegida, portanto, nos dá a noção do potencial de ação da política de Assistência Social quando esta é reconhecida como tal pela CF.88. Em 1981 havia uma enorme distância entre os estados, representada pela amplitude dos extremos. Naquele ano, encontramos São Paulo ${ }^{3}$ com 18,6\% de pessoas abaixo da linha da pobreza e no outro extremo o Piauí com mais de cinco vezes esse percentual, chegando a $82,9 \%$ de sua população em situação de pobreza.

A tendência encontrada na década de 1980 é muito diferente daquela vista a partir de $1990 \mathrm{em}$ diante. A abrupta queda no ano de 1986, provavelmente, deve-se aos efeitos do Plano Cruzado. Uma inflexão forte só acontece a partir dos anos 2000, em especial 2003/2004, como pode ser visto no Gráfico 2:

\section{Gráfico 2 \\ Taxa de pobreza segundo região do país (\%) \\ $1981 \cdot 2012$}

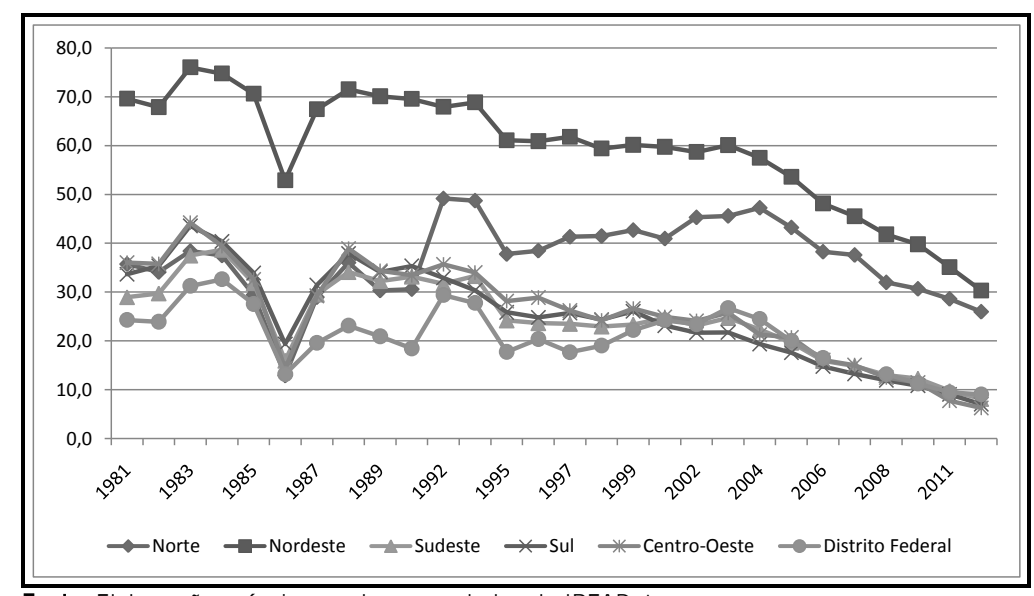

Fonte: Elaboração própria com base em dados do IPEAData.

Na década de 1980 há um empobrecimento geral da população, já a partir de meados de 1990 até 2002 a tendência geral é de queda, mas quando olhamos por estado vemos muita diversidade nas trajetórias. É a partir de 2003 que observamos uma queda generalizada. No entanto, os estados do sul, sudeste e centro-oeste apresentaram taxas de diminuição muito mais elevadas do que o resto do país. É nos estados do norte que a melhoria ocorre em ritmo menos acelerado, quando ocorre, porque no

${ }^{3}$ Informação retirada do site do IBGE: "Até 2004, a PNAD investigava o Brasil inteiro, com exceção das áreas rurais de Rondônia, do Acre, do Amazonas, de Roraima, do Pará e do Amapá que, em conjunto, abrigavam cerca de 3\% da população do País." Portanto, o baixo índice de Roraima, por exemplo, não considera boa parte de sua população e não nos permite nenhuma ilação. 
Amazonas, em Roraima e no Amapá o que se observa é uma piora no indicador. Nos anos 2000 a diminuição da pobreza é sensível. Em 2012, Santa Catarina lidera com 4,21\% da população abaixo da linha de pobreza e o Maranhão em última posição com 41,32\% (ou seja, menos 35 pontos percentuais). Cabe ressaltar que Piauí tem nesse período uma queda de 53 pontos percentuais, saindo de 82,9\% para 29,58\%. No seu conjunto, os estados do nordeste diminuíram a pobreza em cerca de 30 pontos percentuais, passando de uma média de $70 \%$ para uma média de $30 \%$ de pessoas em situação de pobreza.

A Tabela 1 permite ver em números que a melhora no indicador se dá a partir de 2003 em todos os estados. Entre 1981 e 1995 e entre 1995 e 2003 há trajetórias distintas de melhora do indicador (negativo) e de piora (positivo) entre os estados. Mas, o crescimento negativo do índice entre 2003 e 2012, ou seja, a diminuição da pobreza se dá em todos os estados com uma magnitude não vista anteriormente em nenhum estado, apesar de que vemos a diminuição média nos estados do norte e nordeste ser a metade da vista no resto do país. 
SÁTYRO, N. G. D. Padrões distintos de bem-estar no Brasil: uma análise temporal

Tabela 1

Disparidade na Taxa de pobreza segundo estados do país (\%) 1981.2012

\begin{tabular}{|c|c|c|c|c|c|c|c|c|c|c|c|}
\hline Estado & $Y_{i}(81)^{b}$ & $Y_{i}(95)$ & $Y_{i}(03)$ & $Y_{i}(12)^{b}$ & Ranking $81 / 12^{c}$ & $? R^{d}$ & $\begin{array}{c}\text { Crescimento } \\
\text { anual } 81 / 95 \\
(\%)^{\mathrm{e}}\end{array}$ & $\begin{array}{c}\text { Crescimento } \\
\text { anual } 95 / 03 \\
(\%)^{\mathrm{e}}\end{array}$ & $\begin{array}{c}\text { Crescimento } \\
\text { anual 03/12 } \\
(\%)^{\mathrm{e}}\end{array}$ & $\begin{array}{l}Y_{i} / \\
Y_{S P} \\
(81)^{f}\end{array}$ & $\begin{array}{c}Y_{i} / \\
Y_{\mathrm{SC}} \\
(12)^{g}\end{array}$ \\
\hline \multicolumn{12}{|l|}{ Norte } \\
\hline Rondônia & 27,61 & 33,68 & 35,69 & 18,31 & $5 / 12$ & -7 & 1,42 & 0,34 & $-7,42$ & 1,48 & 4,35 \\
\hline Acre & 44,64 & 33,40 & 44,64 & 30,32 & $15 / 24$ & -9 & $-2,07$ & 1,71 & $-4,30$ & 2,40 & 7,20 \\
\hline Amazonas & 28,69 & 38,98 & 49,54 & 29,84 & $6 / 23$ & -17 & 2,19 & 1,41 & $-5,63$ & 1,54 & 7,09 \\
\hline Roraima & 15,27 & 13,39 & 41,21 & 24,35 & $1 / 14$ & -13 & $-0,94$ & 6,61 & $-5,84$ & 0,82 & 5,78 \\
\hline Pará & 45,73 & 47,23 & 49,84 & 29,24 & $16 / 21$ & -5 & 0,23 & 0,32 & $-5,92$ & 2,46 & 6,95 \\
\hline Amapá & 52,40 & 36,03 & 46,00 & 27,41 & $17 / 17$ & 0 & $-2,68$ & 1,44 & $-5,75$ & 2,82 & 6,51 \\
\hline Tocantins & $69,01^{\mathrm{a}}$ & 61,73 & 52,08 & 22,36 & $23 / 13$ & 10 & $-0,80$ & $-1,00$ & $-9,39$ & 3,71 & 5,31 \\
\hline \multicolumn{12}{|l|}{ Norde ste } \\
\hline Maranhão & 76,99 & 68,88 & 65,87 & 41,32 & $26 / 27$ & -1 & $-0,80$ & $-0,26$ & $-5,18$ & 4,14 & 9,81 \\
\hline Piauí & 82,90 & 68,16 & 61,80 & 29,58 & $27 / 22$ & 5 & $-1,40$ & $-0,58$ & $-8,19$ & 4,46 & 7,02 \\
\hline Ceará & 72,94 & 60,51 & 57,24 & 28,47 & $24 / 20$ & 4 & $-1,34$ & $-0,33$ & $-7,76$ & 3,92 & 6,76 \\
\hline Rio Gde. do Norte & 66,05 & 54,87 & 55,89 & 25,23 & $21 / 15$ & 6 & $-1,33$ & 0,11 & $-8,84$ & 3,55 & 5,99 \\
\hline Paraíba & 73,17 & 57,81 & 57,29 & 28,21 & $25 / 19$ & 6 & $-1,68$ & $-0,05$ & $-7,87$ & 3,93 & 6,70 \\
\hline Pernambuco & 62,76 & 58,53 & 62,05 & 28,17 & $19 / 18$ & 1 & $-0,50$ & 0,34 & $-8,78$ & 3,37 & 6,69 \\
\hline Alagoas & 64,48 & 62,06 & 67,39 & 34,64 & $20 / 26$ & -6 & $-0,27$ & 0,49 & $-7,39$ & 3,47 & 8,23 \\
\hline Sergipe & 66,44 & 57,68 & 52,92 & 26,21 & $22 / 16$ & 6 & $-1,01$ & $-0,51$ & $-7,81$ & 3,57 & 6,22 \\
\hline Bahia & 60,68 & 61,19 & 60,28 & 31,01 & $18 / 25$ & -7 & 0,06 & $-0,09$ & $-7,38$ & 3,26 & 7,37 \\
\hline \multicolumn{12}{|l|}{ Sudeste } \\
\hline Minas Gerais & 37,08 & 28,87 & 26,24 & 7,22 & $12 / 6$ & 6 & $-1,79$ & $-0,56$ & $-14,34$ & 1,99 & 1,71 \\
\hline Espírito Santo & 33,78 & 28,59 & 26,12 & 6,00 & $10 / 4$ & 6 & $-1,19$ & $-0,53$ & $-16,33$ & 1,82 & 1,43 \\
\hline Rio de Janeiro & 26,45 & 23,93 & 24,87 & 12,26 & $4 / 11$ & -7 & $-0,71$ & 0,23 & $-7,86$ & 1,42 & 2,91 \\
\hline São Paulo & 18,60 & 15,41 & 21,60 & 7,05 & $2 / 5$ & -3 & $-1,34$ & 1,99 & $-12,45$ & 1,00 & 1,67 \\
\hline \multicolumn{12}{|l|}{ Sul } \\
\hline Paraná & 40,61 & 30,95 & 26,13 & 7,79 & $13 / 8$ & 5 & $-1,94$ & $-1,00$ & $-13,45$ & 2,18 & 1,85 \\
\hline Santa Catarina & 29,72 & 21,54 & 14,83 & 4,21 & $7 / 1$ & 6 & $-2,30$ & $-2,20$ & $-13,99$ & 1,60 & 1,00 \\
\hline Rio Gde. do Sul & 30,66 & 25,08 & 24,27 & 9,11 & $8 / 10$ & -2 & $-1,43$ & $-0,19$ & $-10,89$ & 1,65 & 2,16 \\
\hline \multicolumn{12}{|l|}{ Centro-Oeste } \\
\hline Mato Grosso do Sul & 32,15 & 26,48 & 24,26 & 5,50 & $9 / 2$ & 7 & $-1,39$ & $-0,51$ & $-16,49$ & 1,73 & 1,31 \\
\hline Mato Grosso & 34,10 & 27,23 & 27,17 & 7,45 & $11 / 7$ & 4 & $-1,61$ & $-0,01$ & $-14,37$ & 1,83 & 1,77 \\
\hline Goiás & 41,85 & 30,70 & 25,84 & 5,90 & $14 / 3$ & 11 & $-2,21$ & $-1,01$ & $-16,41$ & 2,25 & 1,40 \\
\hline Distrito Federal & 24,29 & 17,78 & 26,74 & 9,08 & $3 / 9$ & -6 & $-2,23$ & 2,40 & $-12,00$ & 1,31 & 2,16 \\
\hline
\end{tabular}

Fonte: Elaboração própria com base em dados do IPEAData.

Notas:

a - Para o estado de Tocantins os dados referem-se ao ano de 1992, quando inicia sua série histórica.

b - Pobreza - taxa de pobreza. Definição da variável no Quadro 1.

c - Ranking por ordem crescente de taxa de pobreza, comparação entre os rankings de 1981 e 2012.

d - Variação de posição - valor negativo significa piora de posição. 


\section{OPINIÃO PÚBLICA, Campinas, vol. 20, no 2, agosto, 2014, p.219-251}

e - Taxa média de crescimento; calculada pela fórmula In(Final)-In(Inicial)/t, sendo t o número de anos entre as observações inicial e final.

f. Taxa de Pobreza relativa a São Paulo, $y$ il $y_{R R}$, sendo yi a taxa de pobreza da Unidade Federativa i e $y_{S P}$ a taxa de pobreza de São Paulo, em 1981.

g. Taxa de Pobreza relativa a Santa Catarina, yi/ySC, sendo yi a taxa de pobreza da Unidade Federativa i e ySC a taxa de pobreza de Santa Catarina, em 2012.

\section{Educação}

Para analisar o nível de bem-estar encontrado nos estados, analisaremos as condições de formação de capital humano por meio das condições de saúde e educação da população. Consideramos aqui que a evolução dos indicadores de educação nos dá uma pista sobre as políticas educacionais ali empreendidas, ou seja, do investimento em políticas educacionais que foi feito pelo estado. Em função dos nossos objetivos a análise do nível educacional da população é importante para saber que tipo de estado de bem-estar está implantado em uma determinada sociedade. Como já argumentava Marshall:

"a educação das crianças está diretamente relacionada com a cidadania, e, quando o Estado garante que todas as crianças serão educadas, este tem em mente as exigências e a natureza da cidadania. (...) O direito à educação é um direito social de cidadania genuíno porque o objetivo da educação durante a infância é moldar o adulto em perspectiva" (MARSHALL, 1967, p.73).

Ou seja, "a educação é um pré-requisito necessário da liberdade civil" (MARSHALL, 1967, p.73). Dessa forma, a educação é uma das políticas constitutivas de um pacote mínimo a ser oferecido pelo Estado consensual na visão daqueles que concordam que deve haver intervenção estatal.

Os melhores indicadores para o nosso propósito são aqueles que nos revelam a educação da população de 7 a 14 anos, uma vez que a Constituição instituiu o direito de todas as crianças nessa faixa etária à educação e, portanto, a obrigatoriedade da ação do Estado nessa área. Cabe ressaltar que após a CF.88 a obrigatoriedade do ensino de acordo com a idade passou por quatro modificações: LDB de 1996 - tempo mínimo de estudo de 8 anos (7 a 14 anos); Lei 11.114 de 2005 - institui a obrigatoriedade a partir de 6 anos no Ensino Fundamental; Lei 11.274 de 2006 torna obrigatório 9 anos de ensino a partir dos 6 anos. Em 2009, aprovação da E. C. n59 (em vigor atualmente) amplia a obrigatoriedade da Educação Básica para faixa de 4 a 17 anos, agregando Pré-Escola, Ensino Fundamental e Médio.

Assim, analisaremos a frequência de crianças entre 7 e 14 anos de idade e a taxa de analfabetismo de crianças de 10 a 14 anos. Alguém poderia argumentar que o estado, enquanto ente federativo, não é uma boa unidade de análise na medida em que não é responsável pelo Ensino Fundamental. Todavia, apesar da comparação ser entre os estados (e não municípios) a análise se volta para a ação do Estado, mostrando que no nível subnacional há dinâmicas que levam a acessos diferenciados a serviços.

Tanto o percentual de frequência entre as crianças de 7 a 14 anos quanto a taxa de analfabetismo para pessoas de 10 a 14 anos mostradas graficamente sugerem a importância da mudança de regras e da intervenção pública com fins de bem-estar. A partir dos Gráficos 2 e 3 podemos ver que uma inflexão maior se dá a partir de 1997/1998, quando o governo Fernando Henrique Cardoso 
alcança a meta de universalização do Ensino Fundamental, ou seja, consegue colocar mais de $98 \%$ das crianças de 7 a 14 anos na escola, conforme determinava a Constituição. Os resultados dessa ação são vistos nos anos seguintes.

Gráfico 3

Taxa de Analfabetismo na faixa etária de 10 a 14 anos segundo região do país (\%) 1981-2012

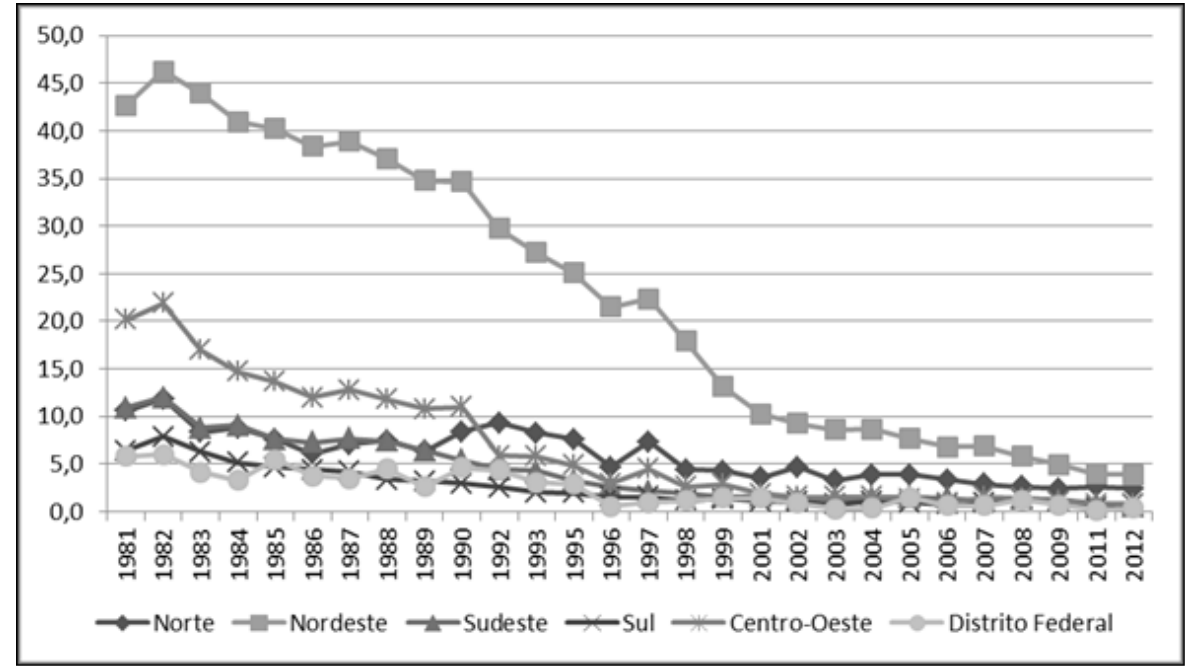

Fonte: Elaboração própria com base em dados do IPEAData.

Gráfico 4

Frequência escolar na faixa etária de 7 a 14 anos segundo região do país (\%) 1981-2012

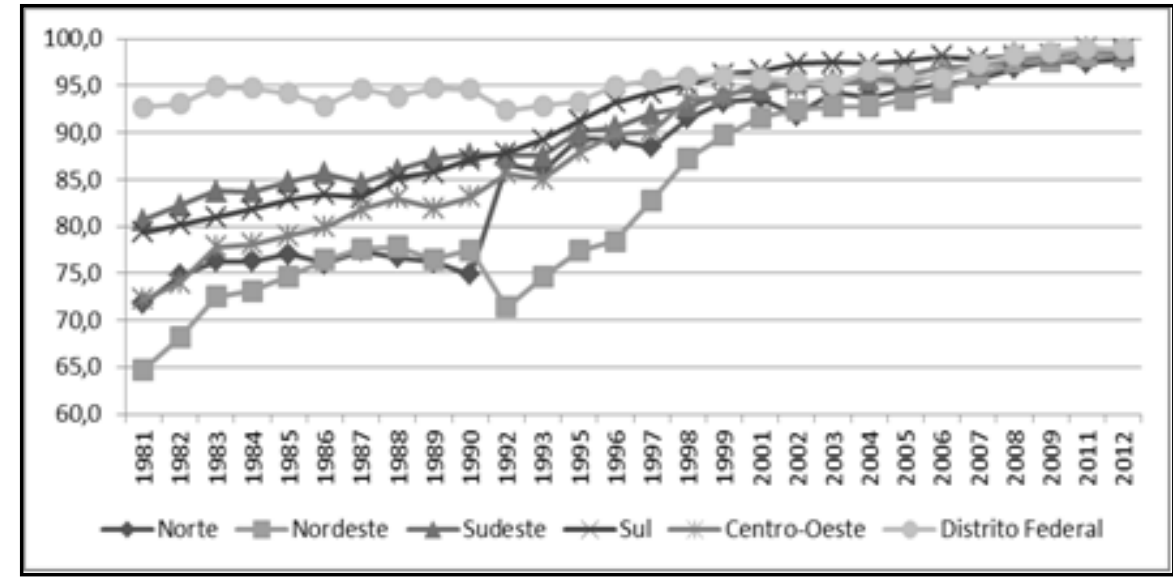

Fonte: Elaboração própria com base em dados do IPEAData.

No nível educacional observamos que a inclinação e a tendência encontrada na década de 1980 é muito diferente daquela vista a partir de 1990. De acordo com a Tabela 2, de Disparidades em Analfabetismo, na década de 1980 há tendências diferentes entre os estados: Rondônia, Mato Grosso do 
Sul, Amapá e Paraná, por exemplo, destacam-se por já empreenderem ali uma diminuição significativa no percentual de analfabetos. Os estados do sul e do sudeste apresentam uma diminuição menos acelerada do que os estados acima referidos mas bem mais acelerada do que os estados nordestinos, que apresentam uma taxa de crescimento ainda que negativa, nada expressiva. Esse quadro se modifica inteiramente no segundo período analisado (1995-2002). Ainda observa-se uma diminuição do número de analfabetos em todos os estados e há uma variação muito grande no ritmo de crescimento anual. Entretanto, agora os estados nordestinos apresentam um crescimento maior do que o restante do país. Em 2012 o quadro geral é bem melhor. Os estados nordestinos e nortistas continuam abaixo da média nacional, mas trata-se de outro cenário. Houve uma diminuição clara entre os extremos apresentados uma vez que Amapá e São Paulo apresentam, respectivamente, 0,28\% e 0,38\% de analfabetos nessa faixa (10 a 14 anos) contra 6,18\% no Rio Grande do Norte. Piauí mostrou uma melhora considerável passando dos $51,76 \%$ em 1981 para $3,79 \%$. 
SÁTYRO, N. G. D. Padrões distintos de bem-estar no Brasil: uma análise temporal

Tabela 2

Disparidades na Taxa de Analfabetismo na faixa etária de 10 a 14 anos 1981-2012

\begin{tabular}{|c|c|c|c|c|c|c|c|c|c|c|c|}
\hline Estado & $Y_{i}(81)^{\phi}$ & $Y_{i}(95)^{b}$ & $Y_{i}(03)^{b}$ & $Y_{i}(12)^{b}$ & Ranking81/12 & $? R^{d}$ & $\begin{array}{c}\text { Crescimento } \\
\text { anual } 81 / 95 \\
(\%)^{e}\end{array}$ & $\begin{array}{c}\text { Crescimento } \\
\text { anual 95/03 } \\
(\%)^{e}\end{array}$ & $\begin{array}{c}\text { Crescimento } \\
\text { anual 03/12 } \\
(\%)^{e}\end{array}$ & $\begin{array}{c}Y_{i} / Y_{S P} \\
(81)^{f}\end{array}$ & $\begin{array}{l}Y_{i} / Y_{A P} \\
(12)^{g}\end{array}$ \\
\hline \multicolumn{12}{|l|}{ Norte } \\
\hline Rondônia & 12,71 & 0,79 & 0,63 & 0,94 & $10 / 12$ & -2 & $-19,88$ & $-2,70$ & 4,34 & 2,74 & 3,38 \\
\hline Acre & 22,58 & 17,19 & 7,16 & 4,61 & $17 / 25$ & -8 & $-1,95$ & $-10,94$ & $-4,89$ & 4,87 & 16,67 \\
\hline Amazonas & 16,02 & 6,42 & 3,28 & 4,32 & $12 / 23$ & -11 & $-6,53$ & $-8,41$ & 3,05 & 3,46 & 15,59 \\
\hline Roraima & $3,51^{a}$ & 1,18 & 0,38 & 1,55 & $1 / 15$ & -14 & $-9,93$ & $-14,26$ & 15,75 & 0,76 & 5,61 \\
\hline Pará & 15,92 & 8,72 & 5,92 & 3,79 & $11 / 20$ & -9 & $-4,30$ & $-4,83$ & $-4,97$ & 3,44 & 13,68 \\
\hline Amapá & 6,99 & 1,45 & 0,75 & 0,28 & $6 / 1$ & 5 & $-11,23$ & $-8,24$ & $-11,08$ & 1,51 & 1,00 \\
\hline Tocantins & $20,52^{2}$ & 17,55 & 2,10 & 1,50 & $16 / 14$ & 2 & $-5,20$ & $-26,55$ & $-3,76$ & 4,43 & 5,40 \\
\hline \multicolumn{12}{|l|}{ Nordeste } \\
\hline Maranhão & 45,27 & 28,29 & 12,17 & 5,09 & $25 / 26$ & -1 & $-3,36$ & $-10,55$ & $-9,69$ & 9,77 & 18,37 \\
\hline Piauí & 51,76 & 36,68 & 8,31 & 3,79 & $27 / 21$ & 6 & $-2,46$ & $-18,57$ & $-8,71$ & 11,17 & 13,71 \\
\hline Ceará & 47,35 & 23,70 & 6,24 & 2,13 & $26 / 16$ & 10 & $-4,94$ & $-16,68$ & $-11,92$ & 10,22 & 7,71 \\
\hline Rio Gde. do Norte & 39,81 & 18,47 & 5,95 & 6,18 & $21 / 27$ & -6 & $-5,49$ & $-14,17$ & 0,43 & 8,59 & 22,32 \\
\hline Paraíba & 43,11 & 21,85 & 6,94 & 3,80 & $24 / 22$ & 2 & $-4,85$ & $-14,33$ & $-6,70$ & 9,31 & 13,73 \\
\hline Pernambuco & 42,30 & 21,71 & 5,87 & 3,27 & $23 / 19$ & 4 & $-4,76$ & $-16,36$ & $-6,50$ & 9,13 & 11,81 \\
\hline Alagoas & 41,89 & 34,32 & 8,86 & 4,59 & $22 / 24$ & -2 & $-1,42$ & $-16,93$ & $-7,30$ & 9,04 & 16,60 \\
\hline Sergipe & 36,93 & 20,43 & 2,54 & 3,23 & $20 / 18$ & 2 & $-4,23$ & $-26,05$ & 2,67 & 7,97 & 11,67 \\
\hline Bahia & 35.57 & 20.53 & 4.84 & 2.68 & $19 / 17$ & 2 & $-3,93$ & $-18,06$ & $-6,56$ & 7,68 & 9,69 \\
\hline \multicolumn{12}{|l|}{ Sudeste } \\
\hline Minas Gerais & 12,47 & 3,96 & 1,06 & 0,77 & $9 / 7$ & 2 & $-8,19$ & $-16,44$ & $-3,51$ & 2,69 & 2,80 \\
\hline Espírito Santo & 18,08 & 5,38 & 1,78 & 0,52 & $13 / 4$ & 9 & $-8,65$ & $-13,83$ & $-13,65$ & 3,90 & 1,88 \\
\hline Rio de Janeiro & 8,56 & 2,41 & 0,87 & 0,61 & $7 / 6$ & 1 & $-9,06$ & $-12,66$ & $-3,94$ & 1,85 & 2,22 \\
\hline São Paulo & 4,63 & 1,31 & 0,84 & 0,38 & $2 / 2$ & 0 & $-9,01$ & $-5,52$ & $-8,93$ & 1,00 & 1,36 \\
\hline \multicolumn{12}{|l|}{ Sul } \\
\hline Paraná & 8,79 & 2,09 & 0,87 & 0,87 & $8 / 11$ & -3 & $-10,27$ & $-10,93$ & $-0,04$ & 1,90 & 3,13 \\
\hline Santa Catarina & 4,96 & 1,95 & 0,72 & 0,53 & $3 / 5$ & -2 & $-6,67$ & $-12,52$ & $-3,29$ & 1,07 & 1,92 \\
\hline Rio Gde. do Sul & 5,50 & 1,80 & 1,30 & 0,95 & $4 / 13$ & -9 & $-7,98$ & $-4,06$ & $-3,46$ & 1,19 & 3,44 \\
\hline \multicolumn{12}{|c|}{ Centro-Oeste } \\
\hline Mato Grosso do Sul & 18,19 & 3,69 & 1,38 & 0,85 & $14 / 10$ & 4 & $-11,39$ & $-12,26$ & $-5,45$ & 3,93 & 3,06 \\
\hline Mato Grosso & 22,84 & 6,12 & 1,46 & 0,85 & $18 / 9$ & 9 & $-9,41$ & $-17,95$ & $-6,03$ & 4,93 & 3,06 \\
\hline Goiás & 19,39 & 4,80 & 1,89 & 0,84 & $15 / 8$ & 7 & $-9,97$ & $-11,65$ & $-8,98$ & 4,19 & 3,05 \\
\hline Distrito Federal & 5,82 & 2,87 & 0,64 & 0,39 & $5 / 3$ & 2 & $-5,05$ & $-18,82$ & $-5,56$ & 1,26 & 1,39 \\
\hline
\end{tabular}

Fonte: Elaboração própria com base em dados do IPEAData.

Notas:

a - Para o estado de Tocantins os dados referem-se ao ano de 1992 para o qual inicia sua série histórica. Para o estado de Roraima os dados trabalhados são de 1984 a 2012.

b - Analfabetos - pessoas 10 a 14 anos - (\%). Definição da variável no Quadro 1.

c - Ranking por ordem crescente de Analfabetismo em 1981 e 2012.

d - Variação de posição - valor negativo significa piora de posição.

e - Taxa média de crescimento; calculada pela fórmula $\ln ($ Final)-In(Inicial)/t, sendo t o número de anos entre as observações inicial e final. 
f- Percentual de pessoas de 10 a 14 anos que são analfabetas relativo a São Paulo, yil $y_{S P}$, sendo $y i$ a taxa de analfabetismo de pessoas de 10 a 14 anos da Unidade Federativa i e $y_{S P}$ a taxa de analfabetismo de pessoas de 10 a 14 anos de São Paulo, no ano de 1981.

g. Percentual de pessoas de 10 a 14 anos que são analfabetas relativo a Amapá, yi/ $y_{A P}$, sendo yi a taxa de analfabetismo de pessoas de 10 a 14 anos da Unidade Federativa i e $y_{A P}$ a taxa de analfabetismo de pessoas de 10 a 14 anos de Amapá, no ano de 2012.

Mas, uma coisa é ensinar a ler e a escrever um bilhete simples (embora isso não seja simples), outra coisa é fazer com que as pessoas completem integralmente seus anos letivos com sucesso ano após ano. A disparidade encontrada no nível educacional entre os estados também pode ser vista pelo número de anos de estudo das pessoas de 25 anos ou mais e, nesse caso, as distâncias relativas se mantêm. O Distrito Federal lidera em todo o percurso analisado. Enquanto o DF apresenta 6,15 anos completos de estudo em 1981, um cidadão do Piauí não chegava a ter 2 anos de estudo $(1,78)$, ou seja, tinha apenas cerca de um terço dos anos de estudos do cidadão médio habitante do DF. O ritmo de crescimento anual é relativamente próximo, o que faz com que se mantenham as distâncias relativas entre os estados. Assim, em 2007, dos estados nordestinos, somente Sergipe consegue chegar à marca dos seis anos de estudo nessas três décadas. Todos os demais estados das outras regiões ultrapassam essa marca. Em 2012, dos 16 estados do norte e nordeste, apenas 5 não alcançaram os 6 anos, mas já estão próximos, todos acima de 5,5 alagoanos. O Gráfico 5 confirma uma das hipóteses levantadas, a manutenção das diferenças relativas mesmo diante da melhora em termos reais. Continuamos dois Brasis.

\section{Gráfico 5}

Anos de Estudo - pessoas com 25 anos ou mais - segundo região do país (\%) 1981-2012

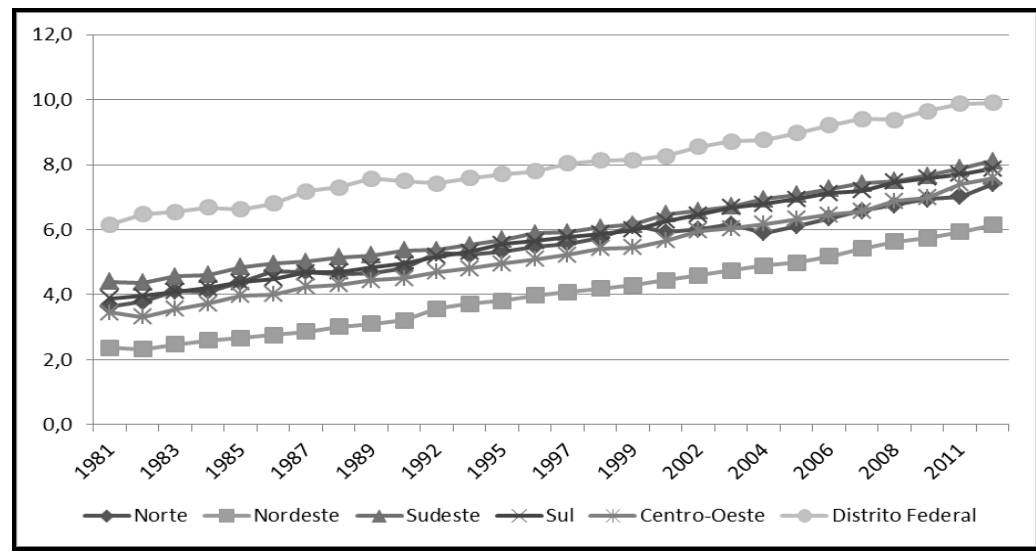

Fonte: Elaboração própria com base em dados do IPEAData.

Entretanto, é importante frisar que já na década de 1980 o nordeste bem como Roraima, Amapá e Rondônia apresentam um ritmo ligeiramente mais acelerado do que o restante do país. Na década de 1990 há uma desaceleração na taxa de crescimento anual já esperada por causa do que 
SÁTYRO, N. G. D. Padrões distintos de bem-estar no Brasil: uma análise temporal

chamamos ganho marginal decrescente. Em teoria, é mais fácil conseguir aumentar de 1 ano de estudo para 3 anos de estudo do que de 3 anos para 6 anos de estudo, por exemplo.

Para entendermos a sustentabilidade do crescimento desse capital escolar podemos observar no Gráfico 6, a frequência escolar de adolescentes entre 15 e 17 anos com 8 ou mais anos de estudo para 1981 a 2006. A partir de 1994-1995 observa-se uma inflexão substantiva nessa frequência. Ou seja, nossos adolescentes estão estudando mais e permanecendo mais na escola, entretanto, os adolescentes nordestinos e nortistas o fazem bem menos do que aqueles oriundos do sul e sudeste.

\section{Gráfico 6 \\ Frequência escolar de pessoas entre 15 e 17 anos com 8 ou mais anos de estudo - segundo região do país (\%) $1981 \cdot 2006$}

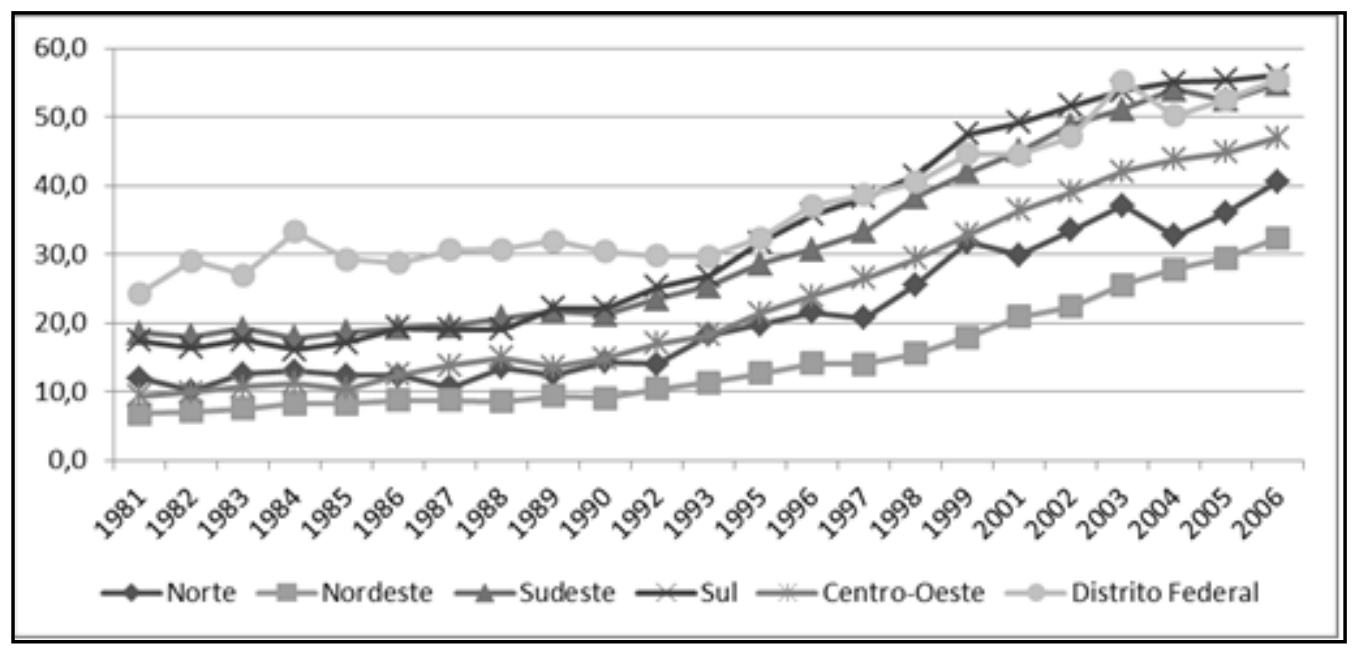

Fonte: Elaboração própria com base em dados do IPEAData.

Vimos aqui a existência de padrões muito distintos no nível educacional da população dos diferentes estados, o que confirma a existência de regimes de políticas educacionais muito distintas no primeiro período analisado em relação àquele pós-Constituição. Em países que possuem um Estado de Bem-Estar consolidado e com características universalistas como a Inglaterra a educação obrigatória foi o primeiro passo ainda no século XIX para o estabelecimento de direitos sociais no século XX. Infelizmente, esse direito do cidadão e dever do Estado brasileiro só começa a ser reconhecido na CF.88 e só é alcançado 10 anos depois.

Saúde

A CF.88 trouxe uma mudança estruturante para a política de saúde: determinou que esta seria um direito universal, ou seja, a prestação de assistência médica não mais seria securitária, mas um direito de todos, determinando no próprio texto constitucional a criação de um Sistema Único de Saúde. É claro que, com um legado frágil na prestação de serviços em função da trajetória da área, a montagem de um sistema de saúde nacional para um país do porte do Brasil, e a produção de resultados, levou tempo e ainda não está consolidada. Naquele momento, os atores privados eram muito fortes e bem posicionados dentro da máquina pública e a capacidade administrativa tanto no nível federal quanto nos 
outros âmbitos de governo levou tempo para ser construída. Importante ressaltar também que o legado era de uma saúde securitária e, portanto, ausente para grande parte da população brasileira. As consequências disto podem ser vistas na heterogeneidade dos indicadores de saúde.

Os indicadores de saúde mostram um cenário de muita desigualdade entre os estados brasileiros, mas a tendência geral de melhora nos indicadores sugere que os estados estão se homogeneizando. Mais que isso, as desigualdades colossais na capacidade de permanecer vivo que eram vistas até a década de 1980 já foram superadas. Para fins ilustrativos podemos falar brevemente sobre a infraestrutura de saúde disponível para a população entre os estados comparando o número de médicos residentes por mil habitantes entre os estados brasileiros ${ }^{4}$. Em 1991 o Rio de Janeiro estava com 2,23 médicos por mil habitantes enquanto o Acre tinha algo em torno de 0,17 , ou seja, $8 \%$ em relação ao Rio de Janeiro. No período analisado a melhora geral foi visível, mas o ritmo de crescimento anual variou muito entre os estados. Sergipe se destaca em 2009 com 4,20 médicos/1000, e o Maranhão amarga a última posição com apenas a terça parte disso com 1,3 médicos/1000. Esse indicador reflete as condições gerais da assistência de saúde ofertada nas diferentes regiões que por sua vez impacta na mortalidade infantil. Espera-se que a política atual do governo federal, o Mais Médicos, que tem objetivo de interiorização desses profissionais, surta efeitos importantes nesses indicadores. A melhora na Taxa de Mortalidade infantil por 1000 nascidos vivos é um bom indicador do conjunto de políticas de saúde e de políticas mais amplas como saneamento e outras. 0 Gráfico 7 mostra o nosso percurso nas últimas três décadas:

\footnotetext{
${ }^{4}$ Esses dados podem ser encontrados no Datasus.
} 
Gráfico 7

Taxa de Mortalidade Infantil por mil, segundo região do país (\%) $1985 \cdot 2011$

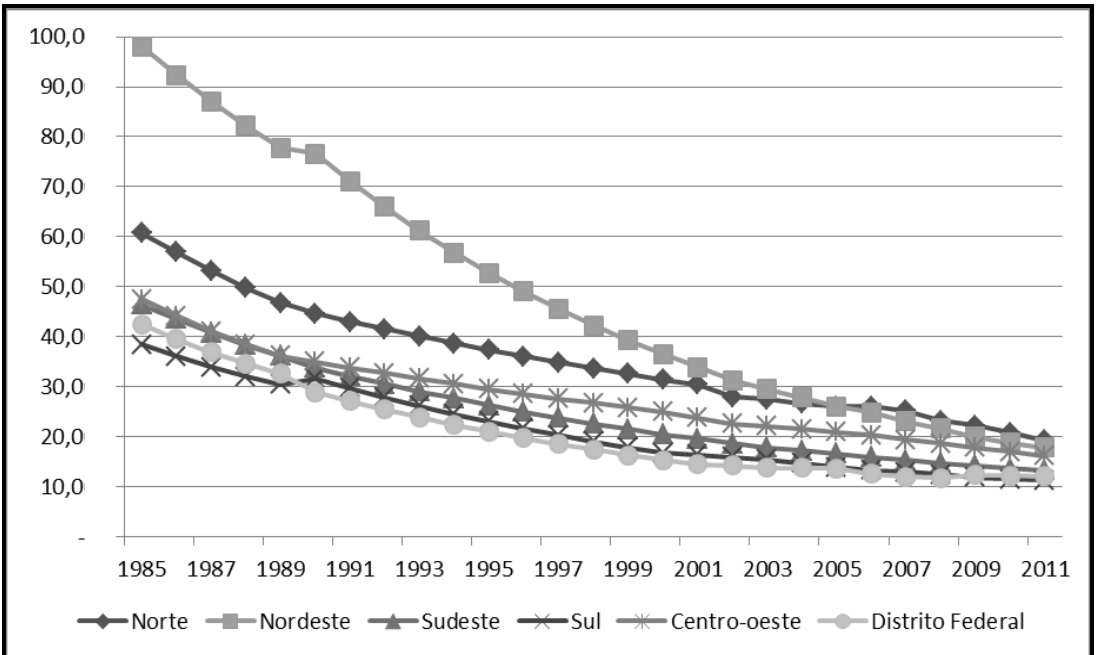

Fonte: Elaboração própria com base em dados do DataSUS.

A análise da Tabela 3 permite observar as disparidades entre o número de óbitos infantis por mil entre os estados. Com o efeito de diminuir as disparidades, vemos que os estados nordestinos têm, em média, as melhores taxas de crescimento durante todo o período, o que diminui sensivelmente os extremos. Os estados do sul e do sudeste estão nas melhores posições do ranking. Em 1985 estima-se que no Rio Grande do Sul morriam cerca de 29,25 crianças em cada 1000 nascidas vivas enquanto em Alagoas esse número quadruplicava chegando a 116,88 mortes infantis. Em termos gerais os números melhoram muito nos anos analisados. Estima-se que em 2011 morriam 10,8 crianças em Santa Catarina enquanto no Amapá ainda morriam cerca de 24,10 crianças a cada mil. Não há como negar que apesar da disparidade entre os estados o pior estado em 2011 apresenta um número que equivale a 1/5 do pior cenário em 1985. Infelizmente, o que os números mostram é que, no nosso melhor cenário, morre o dobro de crianças nordestinas quando comparadas às do sul. 
Tabela 3

Disparidades da Taxa de Mortalidade infantil por mil 1985 a 2011

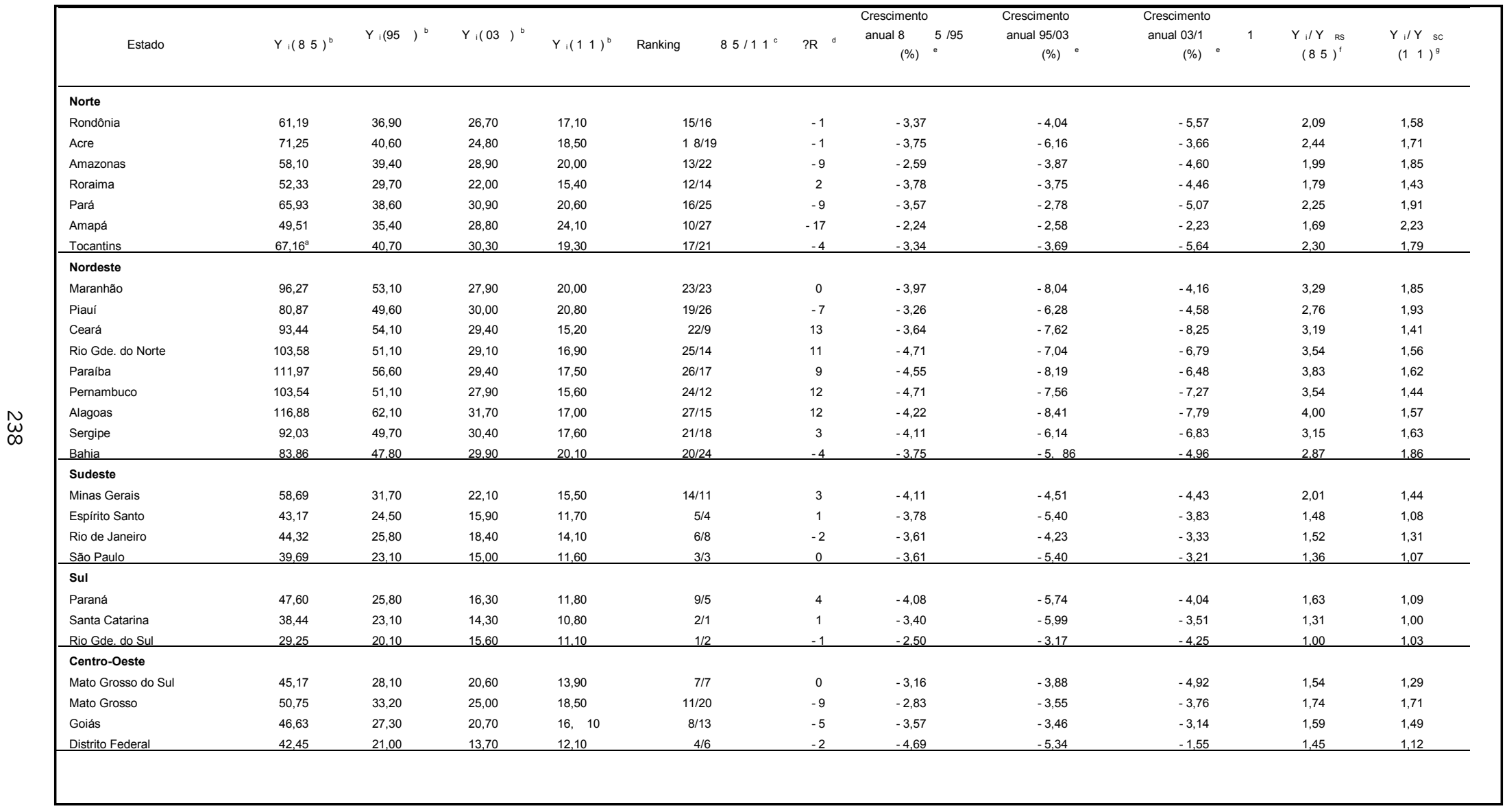

Fonte: Elaboração própria com base nos dados do DataSUS. 


\section{SÁTYRO, N. G. D. Padrões distintos de bem-estar no Brasil: uma análise temporal}

Notas:

a - Para o estado de Tocantins os dados referem-se ao ano de 1992 para o qual inicia sua série histórica.

b - Taxa de mortalidade infantil por mil habitantes. Definição da variável no Quadro 1.

c - Ranking por ordem crescente da Taxa de mortalidade infantil em 1985 e 2011.

d · Variação de posição - valor negativo significa piora de posição.

e - Taxa média de crescimento; calculada pela fórmula $\ln ($ Final) $\ln ($ Inicial)/t, sendo t o número de anos entre as observações inicial e final.

f- Taxa de mortalidade infantil por mil habitantes relativa ao Rio Grande do Sul, $y i / y_{R S}$, sendo yi a taxa de mortalidade infantil por mil habitantes da Unidade Federativa i e $y_{R S}$ a taxa de mortalidade infantil por mil habitantes do Rio Grande do Sul, no ano de 1985.

g. Taxa de mortalidade infantil por mil habitantes relativa a Santa Catarina, $y i / y_{s c}$, sendo $y i$ a taxa de mortalidade infantil por mil habitantes da Unidade Federativa i e $y_{S C}$ a taxa de mortalidade infantil por mil habitantes de Santa Catarina, no ano de 2011.

\section{A dimensão econômica do regime de bem-estar}

O acesso aos serviços básicos, em especial, à educação, determina o capital humano de uma população que está diretamente relacionado com a qualidade de sua inserção no mercado de trabalho. A literatura tem mostrado que essa heterogeneidade educacional (que pode ser vista nas tabelas e gráficos acima) é a causa maior das diferenças de renda assim como do tipo de proteção social. Toda essa análise da melhora das condições básicas vividas pela população brasileira e, portanto, do acesso a serviços básicos deve estar pautada pelo crescimento econômico vivido pelo país na última década. Afinal, como afirmam Huber e Stephens (2001), um dos pilares do EBES é a faceta do regime de produção sobre o qual está estruturado.

Assim, torna-se importante também analisar a estrutura do mercado de trabalho. Veremos aqui duas dimensões distintas: a taxa de crescimento da riqueza dos estados relativa à sua população por meio do PIB per capita e as condições do mercado de trabalho por meio de medida da precariedade dos postos de trabalho.

É claro que os estados estão submetidos e dependentes da política macroeconômica do país e presenciamos momentos muito distintos na economia brasileira nas últimas três décadas. A década de 1980, conhecida como a década perdida, mostrou uma taxa negativa de crescimento no início e uma leve recuperação na segunda metade. Na década de 1990 continua uma queda no crescimento, uma crise generalizada, índices inflacionários dos mais altos do mundo, uma moeda instável e desvalorizada e um acúmulo de sete planos de estabilização fracassados. Com a entrada do então ministro da Fazenda Fernando Henrique Cardoso, ao final do governo Itamar, se alcança a estabilização da moeda e o controle da inflação. O nosso ponto aqui é que, se em termos gerais esse era o quadro do país, a situação variava muito entre os estados e a heterogeneidade dos mercados de trabalho também se constitui tanto um legado quanto uma estrutura a partir da qual se determinam as condições reais de estabelecimento de programas sociais e políticas de investimento no mercado de trabalho. 
Gráfico 8

Crescimento econômico no Brasil-PIB per capita segundo região do país (\%) $1985-2010$

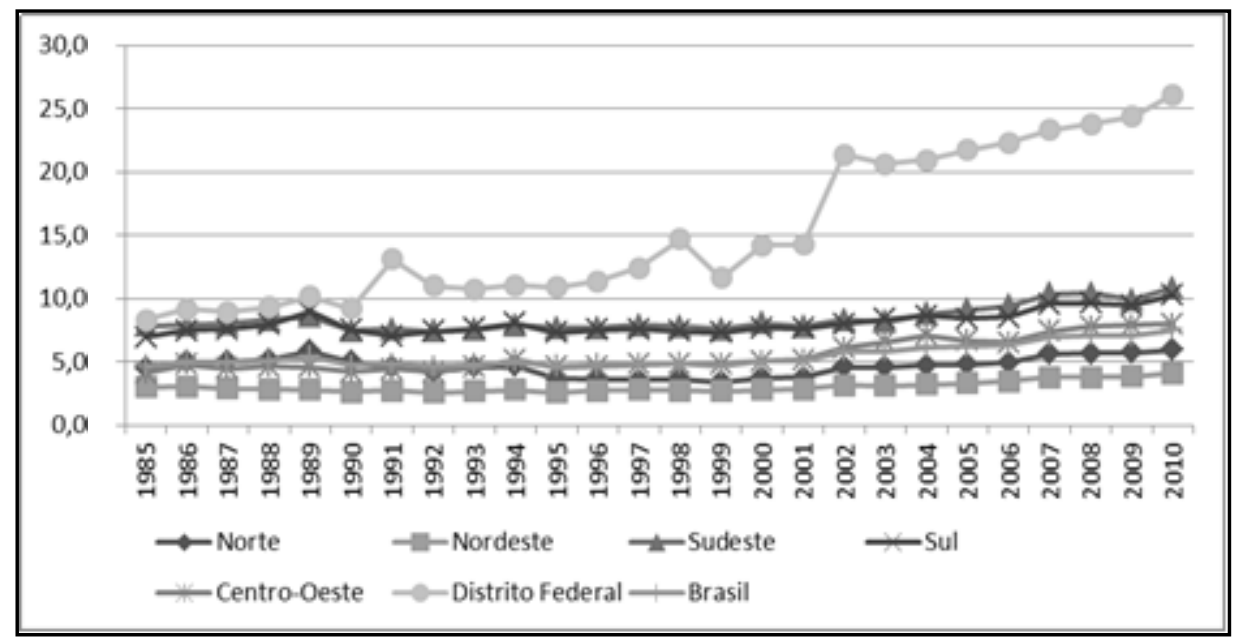

Fonte: Elaboração própria com base em dados do IPEAData.

Por meio da Tabela 4 podemos observar a variação no crescimento econômico entre os estados no período que vai de 1985 a 2010. Observa-se que, também nesse caso, em 1985 havia uma enorme distância entre os estados representada pela amplitude dos extremos. Os PIBs per capita do Piauí e do Maranhão eram apenas $13 \%$ do de São Paulo, passaram-se 25 anos e não houve mudanças significativas nesse cenário relativo. 
SÁTYRO, N. G. D. Padrões distintos de bem-estar no Brasil: uma análise temporal

Tabela 4

Disparidades no PIB per capita

1985.2010

\begin{tabular}{|c|c|c|c|c|c|c|c|c|c|c|c|}
\hline Estado & $Y_{i}(5)^{b}$ & $Y_{i}(95)^{b}$ & $Y_{i}(03)^{b}$ & $Y_{i}(10)^{b}$ & Ranking85/10 & $? \mathrm{R}^{\mathrm{d}}$ & $\begin{array}{c}\text { Crescimento } \\
\text { anual } 85 / 95 \\
(\%)^{e}\end{array}$ & $\begin{array}{c}\text { Crescimento } \\
\text { anual } 95 / 03 \\
(\%)^{e}\end{array}$ & $\begin{array}{c}\text { Crescimento } \\
\text { anual } 03 / 10 \\
(\%)^{e}\end{array}$ & $\begin{array}{c}Y_{i} / Y_{S P} \\
(85)^{f}\end{array}$ & $\begin{array}{l}Y_{i} / Y_{D F} \\
(10)^{g}\end{array}$ \\
\hline \multicolumn{12}{|l|}{ Norte } \\
\hline Rondônia & 5,06 & 3,54 & 4,81 & 6,74 & $12 / 13$ & -1 & $-3,97$ & 3,83 & 4,80 & 0,47 & 0,26 \\
\hline Acre & 3,07 & 3,06 & 3,85 & 5,16 & $21 / 18$ & 3 & $-0,05$ & 2,89 & 4,18 & 0,29 & 0,22 \\
\hline Amazonas & 7,32 & 6,70 & 5,91 & 7,66 & $5 / 11$ & -6 & $-0,98$ & $-1,56$ & 3,71 & 0,68 & 0,30 \\
\hline Roraima & 3,98 & 2,59 & 5,44 & 6,27 & $15 / 14$ & 1 & $-4,80$ & 9,30 & 2,02 & 0,37 & 0,26 \\
\hline Pará & 3,09 & 3,26 & 3,25 & 4,58 & $20 / 21$ & -1 & 0,57 & $-0,04$ & 4,91 & 0,29 & 0,17 \\
\hline Amapá & 4,43 & 4,80 & 4,54 & 5,52 & $13 / 15$ & -3 & 0,90 & $-0,70$ & 2,78 & 0,41 & 0,24 \\
\hline Tocantins & $1.67^{\mathrm{a}}$ & 1,77 & 4,22 & 5,56 & $25 / 15$ & 10 & 0,63 & 10,84 & 3,94 & 0,16 & 0,22 \\
\hline \multicolumn{12}{|l|}{ Nordeste } \\
\hline Maranhão & 1,40 & 1,44 & 2,27 & 3,07 & $27 / 27$ & 0 & 0,33 & 5,68 & 4,32 & 0,13 & 0,13 \\
\hline $\begin{array}{l}\text { Piauí } \\
\text { Ceará }\end{array}$ & $\begin{array}{l}1,40 \\
2,49\end{array}$ & $\begin{array}{l}1,77 \\
2,73\end{array}$ & $\begin{array}{l}2,17 \\
3,03\end{array}$ & $\begin{array}{l}3,16 \\
4,11\end{array}$ & $\begin{array}{l}26 / 26 \\
23 / 23\end{array}$ & $\begin{array}{l}0 \\
0\end{array}$ & $\begin{array}{l}2,56 \\
1,03\end{array}$ & $\begin{array}{l}2,58 \\
1,29\end{array}$ & $\begin{array}{l}5,33 \\
4,39\end{array}$ & $\begin{array}{l}0,13 \\
0,23\end{array}$ & $\begin{array}{l}0,12 \\
0,15\end{array}$ \\
\hline Rio Gde. do Norte & 3,05 & 2,74 & 3,38 & 4,55 & $22 / 22$ & 0 & $-1,18$ & 2,59 & 4,27 & 0,28 & 0,18 \\
\hline Paraíba & 2,02 & 2,42 & 2,92 & 3,78 & $24 / 24$ & 0 & 2,01 & 2,34 & 3,71 & 0,19 & 0,15 \\
\hline Pernambuco & 3,32 & 3,50 & 3,48 & 4,83 & $18 / 20$ & -2 & 0,60 & $-0,06$ & 4,66 & 0,31 & 0,18 \\
\hline Alagoas & 3,21 & 2,28 & 2,78 & 3,51 & $19 / 25$ & -6 & $-3,81$ & 2,46 & 3,36 & 0,30 & 0,14 \\
\hline Sergipe & 5,90 & 3,25 & 4,17 & 5,16 & $9 / 17$ & -8 & $-6,64$ & 3,15 & 3,04 & 0,55 & 0,21 \\
\hline Bahia & 4,23 & 3,24 & 3,67 & 4,91 & $14 / 19$ & -5 & $-2,97$ & 1,57 & 4,15 & 0,39 & 0,18 \\
\hline \multicolumn{12}{|l|}{ Sudeste } \\
\hline Minas Gerais & 5,55 & 5,64 & 5,79 & 8,00 & $10 / 9$ & 1 & 0,19 & 0,32 & 4,61 & 0,52 & 0,31 \\
\hline Espírto Santo & 6,26 & 6,79 & 6,88 & 10,43 & $7 / 6$ & 1 & 0,90 & 0,16 & 5,95 & 0,58 & 0,44 \\
\hline Rio de Janeiro & 8,84 & 8,25 & 9,13 & 11,36 & $2 / 3$ & -1 & $-0,76$ & 1,27 & 3,11 & 0,82 & 0,47 \\
\hline São Paulo & 10,76 & 10,06 & 10,79 & 13,49 & $1 / 2$ & -1 & $-0,74$ & 0,88 & 3,19 & 1,00 & 0,53 \\
\hline \multicolumn{12}{|l|}{ Sul } \\
\hline Paraná & 6,17 & 6,42 & 7,98 & 9,29 & $8 / 7$ & 1 & 0,44 & 2,72 & 2,16 & 0,57 & 0,37 \\
\hline Santa Catarina & 6,82 & 7,17 & 8,59 & 10,89 & $6 / 4$ & 2 & 0,56 & 2,25 & 3,39 & 0,63 & 0,44 \\
\hline Rio Gde. do Sul & 7,83 & 8,37 & 8,57 & 10,53 & $4 / 5$ & -1 & 0,75 & 0,29 & 2,95 & 0,73 & 0,40 \\
\hline \multicolumn{12}{|l|}{ Centro-Oeste } \\
\hline Mato Grosso do Sul & ال 5,09 & 5,46 & 6,40 & 7,93 & $11 / 10$ & 1 & 0,79 & 1,99 & 3,05 & 0,47 & 0,31 \\
\hline Mato Grosso & 3,72 & 4,32 & 7,55 & 8,77 & $16 / 8$ & 8 & 1,67 & 6,99 & 2,13 & 0,35 & 0,39 \\
\hline Goiás & 3,46 & 3,96 & 5,79 & 7,25 & $17 / 12$ & 5 & 1,49 & 4,77 & 3,21 & 0,32 & 0,28 \\
\hline Distrito Federal & 8,32 & 10,89 & 20,64 & 26,10 & $3 / 1$ & 2 & 3,00 & 7,99 & 3,35 & 0,77 & 1,00 \\
\hline
\end{tabular}

Fonte: Elaboração própria com base em dados do IPEAData.

Notas:

a - Para o estado de Tocantins os dados referem-se ao ano de 1989 para o qual inicia sua série histórica.

b - PIB Estadual per capita. Definição da variável no Quadro 1.

c - Ranking por ordem decrescente de PIB Estadual per capita.

d · Variação de posição - valor negativo significa piora de posição.

e - Taxa média de crescimento; calculada pela fórmula In(Final)-In(Inicial)/t, sendo t o número de anos entre as observações inicial e final.

f - PIB estadual per capita relativo a São Paulo, $y$ il $y_{S P}$ sendo yi o PIB estadual per capita da Unidade Federativa i e $y_{S P} O$ PIB estadual per capita de São Paulo, no ano de 1985.

g - PIB estadual per capita relativo ao Distrito Federal, yil yDF, sendo yi PIB estadual per capita da Unidade Federativa i e $y D F$ o PIB estadual per capita do Distrito Federal, no ano de 2010. 
A tendência da economia nos estados encontrada na década de 1980 é muito diferente daquela vista a partir de 1990. Não há um padrão regional dentro das duas grandes tendências de queda e de aumento no crescimento econômico entre 1985 a 1995, com os dois blocos contendo estados de todas as regiões. E mesmo dentro de cada bloco a variação é muito grande. O conjunto de estados que cresceu nesse período também varia na composição e na intensidade como pode ser visto na Tabela 4. Observamos um crescimento negativo em 10 estados incluindo estados do nordeste, do norte e do sudeste. Todavia, no segundo período analisado, o quadro melhora substantivamente. Apenas Amazonas, Amapá, Pernambuco e Pará apresentam uma taxa negativa. Ou seja, o quadro geral da riqueza e da economia melhora nesse momento, mas as discrepâncias ainda são muito fortes. Já quando analisamos o período de 2003 em diante, vemos um crescimento generalizado e o ritmo não encontra padrão regional como também pode ser visto na Tabela 4.

Cabe ver também como o mercado de trabalho absorveu a mão de obra. Para isso, compararemos os estados pelo Grau de Informalidade que nos permite inferir sobre o nível de desproteção das pessoas e, portanto, seu nível de bem-estar social diante de riscos sociais (Gráfico 9 e Tabela 5). Infelizmente, esse indicador só está disponível a partir de 1993, não permitindo analisar a década de 1980 que, com certeza, apresentou níveis altíssimos de informalidade. Em 1993 observamos que São Paulo apresenta o menor grau de informalidade com 39,89\% de trabalhadores informais enquanto o Maranhão apresenta $88,23 \%$ de sua força de trabalho sem as proteções do mercado formal. Há uma melhora no quadro geral mas a um ritmo muito lento e com muita variação. Do conjunto com ritmo anual menos acelerado contra a informalidade destacam-se o Rio de Janeiro pela estagnação e Roraima pelo aumento da informalidade. Entre 1993 e 2003, 11 estados apresentaram aumento da informalidade, não havendo tendência regional dentro desse bloco. Esse cenário muda a partir de 2003 quando há uma diminuição generalizada da informalidade no mercado de trabalho, entretanto, isso acontece a um ritmo mais lento para os estados nordestinos como pode ser visto na Tabela 5.

Gráfico 9

Grau de Informalidade segundo região do país (\%) 1993.2012

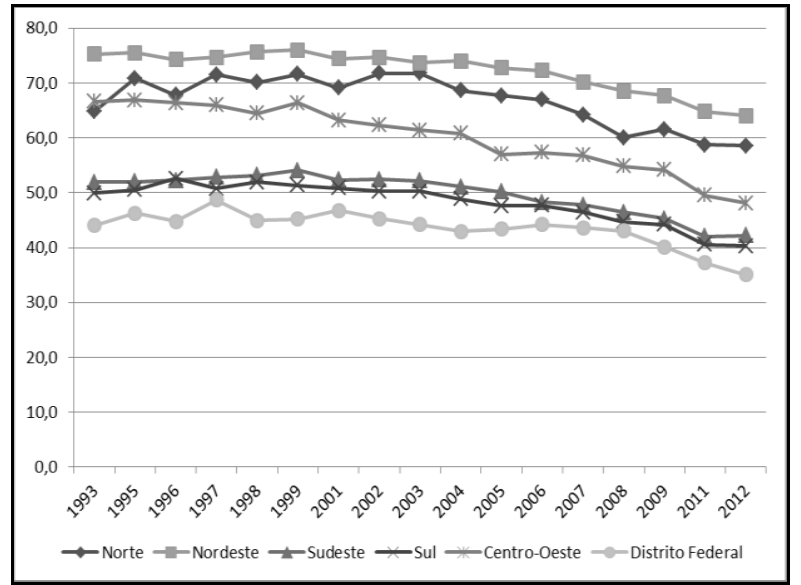

Fonte: Elaboração própria com base em dados do IPEAData. 
SÁTYRO, N. G. D. Padrões distintos de bem-estar no Brasil: uma análise temporal

Tabela 5

Disparidades do Grau de Informalidade

1993-2012

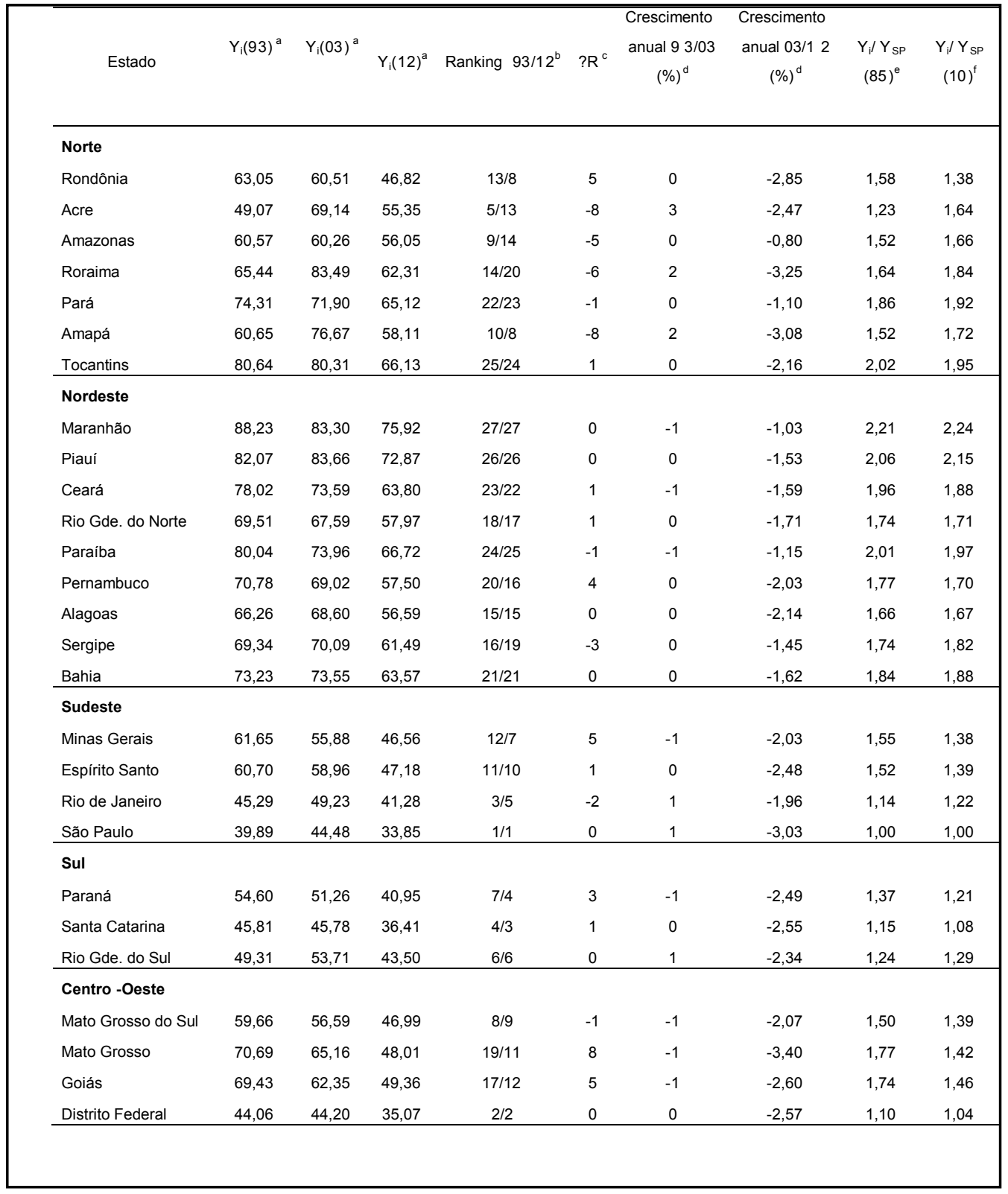

Fonte: Elaboração própria com base em dados do IPEAData.

Notas:

a - Grau de informalidade - definição I. Definição no Quadro 1.

b - Ranking por ordem crescente de Grau de Informalidade dos anos de 1993 e 2012.

c · Variação de posição - valor negativo significa piora da posição no ranking. 


\section{OPINIÃO PÚBLICA, Campinas, vol. 20, no 2, agosto, 2014, p.219-251}

d - Taxa média de crescimento; calculada pela fórmula In(Final)·In(Inicial)/t, sendo t o número de anos entre as observações inicial e final.

e - Grau de informalidade - definição I relativo a São Paulo, yil $y_{S P}$, sendo yi o Grau de informalidade - definição I da Unidade Federativa i e $y_{S P}$ o Grau de informalidade - definição I de São Paulo, no ano de 1993.

f - Grau de informalidade - definição I relativo a São Paulo, yi/ySP, sendo yi o Grau de informalidade - definição I da Unidade Federativa i e ySP o Grau de informalidade - definição I de São Paulo, no ano de 2012.

Vemos que, em 2012, o Maranhão melhorou em 7,3 pontos percentuais, caindo assim para $75,92 \%$ de sua força de trabalho inserida precariamente no mercado, enquanto o Piauí fica com 72,87\% de sua população economicamente ativa desprotegida. Cabe ainda dizer que em 2012 todos os estados do nordeste e todos os do norte, com exceção de Rondônia, ainda possuem mais da metade de sua força de trabalho inserida precariamente.

Em síntese, é crucial para a análise aqui implementada saber tanto sobre o crescimento econômico quanto sobre a forma como a mão de obra está se inserindo no mercado, uma vez que historicamente a proteção social no Brasil foi exclusivamente contributiva, ou seja, se deu pela inserção no mercado de trabalho formal e só após as determinações constitucionais inseriu-se solidariedade no sistema. Importante enfatizar que o seguro-desemprego foi criado em 1986, mas foi reconhecido como direito somente na CF.88, apesar de já ser previsto desde a Constituição de 1946.

Nesse caso, os estados mais ricos também são aqueles que comportam menos informalidade no mercado de trabalho. Concluímos que houve crescimento generalizado na última década, mas o ritmo e a magnitude do crescimento são matizados pela estrutura produtiva pré-existente. Assim como a diminuição na amplitude encontrada em relação à informalidade. Baltar (2000) mostra que a diminuição das diferenças regionais de renda se dá mais pela desaceleração de São Paulo do que pelo crescimento em outros lugares. Essa mesma conclusão o autor tem com relação à demorada inflexão na informalidade. Para ele foram poucas as mudanças estruturais até 2003, reafirmando o peso do legado. Mudanças estruturais só serão vistas a partir de 2003 com a retomada do crescimento e com a geração de postos de trabalho formais.

Os dados sugerem que a manutenção de posições relativas se dá pelo legado. E sugerem também que as melhorias nas áreas sociais se deram em função de determinações constitucionais e da implementação de políticas nas diversas áreas aqui analisadas no decorrer do tempo. Necessitou-se de tempo para que as instituições e os governos começassem a implementar tais mudanças e que estas refletissem nos indicadores.

\section{O agrupamento dos estados em relação aos indicadores utilizados}

Para a identificação dos estados que possuem características semelhantes quanto aos indicadores educacionais, de saúde e de mercado de trabalho aqui utilizados faremos uma análise de agrupamentos. De natureza exploratória, não probabilística, a análise de agrupamentos permite-nos visualizar os estados em função de suas similitudes e dessemelhanças. Segundo Moori e outros,

\footnotetext{
"a análise de agrupamentos (cluster analysis) é uma técnica estatística que permite ao pesquisador separar ou classificar objetos observados em um grupo ou em número específico de subgrupos ou conglomerados (clusters) mutuamente exclusivos, de modo que
} 


\section{SÁTYRO, N. G. D. Padrões distintos de bem-estar no Brasil: uma análise temporal}

os subgrupos formados tenham características de grande similaridade interna e grande dissimilaridade externa" (MooRI et al, 2002).

No primeiro exercício juntaram-se os dois indicadores de educação, o de mortalidade infantil, o de pobreza e o de riqueza; a análise mostra-nos a existência de dois conglomerados de estados no período analisado (1985-2009). Podemos falar claramente de dois Brasis: um Brasil pobre, com altos índices de analfabetismo e mortalidade infantil; taxas estas que, com certeza, apresentam um entrave para o crescimento econômico daqueles estados (cluster número 2). O outro Brasil (cluster 1) é formado por estados onde há taxas bem menores de analfabetismo quando comparadas ao outro conglomerado, ainda que inaceitáveis, e que estão numa situação muito melhor que aqueles que constituem o conglomerado 2. Mas, o que vemos é que há uma homogeneização no tempo, mesmo que os estados nordestinos demorem mais do que a média.

Pode-se dizer que o nordeste se destaca como o grande formador do conglomerado 2, uma vez que a maioria de seus estados permaneceu a maior parte da série temporal analisada neste conglomerado. Do lado oposto, temos os estados das regiões sudeste e sul com uma posição integral no conglomerado 1, além desses podemos citar o caso do Distrito Federal e Mato Grosso do Sul que também estão integralmente no conglomerado 1. Na região norte este mesmo comportamento foi encontrado nos estados de Rondônia, Amazonas, Roraima e Amapá. Conformação esta que contraria o senso comum que sempre junta as regiões norte e nordeste como se compusessem um grupo homogêneo. O que se vê aqui é que existem diferenças substantivas entre os estados dessas regiões no que se refere aos indicadores utilizados. Mato Grosso e Goiás só estão fora no primeiro ano da série.

Entretanto, se pegarmos apenas os indicadores de políticas sociais, o quadro é outro. No segundo exercício utilizamos apenas os dois indicadores de educação mais mortalidade infantil e encontramos 3 (três) diferentes conglomerados mostrando a diversidade de acesso aos serviços básicos indo de estados onde os cidadãos têm acesso mais universalizado aos serviços básicos (conglomerado 1) aos estados onde apenas a menor parte da população tem acesso a esses mesmos serviços (conglomerado 3) e assim as crianças morrem mais do que a média do país e em sua maioria não sabem ler. Se pegarmos os extremos para ilustrar temos Maranhão, Piauí e Alagoas no terceiro conglomerado, só avançando para o segundo conglomerado ao final da década de 1990. Do extremo oposto temos as melhores performances do Rio de Janeiro, São Paulo e Distrito Federal apresentando os melhores indicadores, estando a maior parte no primeiro conglomerado, já desde o início da década de 1990. Temos o bloco do sudeste e sul que começa no segundo conglomerado, mas no decorrer da década de 1990 passa para o primeiro conglomerado. Importante dizer que toda análise exclui os anos que não há dados para algum estado, dessa forma, engloba anos entre 1985-2011.

A pergunta que fica é qual estado se encontra em qual grupo, em qual ano? Ou seja, como se dá a trajetória de pertencimento? O Quadro 2 mostra o pertencimento de cada estado a um grupo ou a outro, em cada ano analisado. Essa análise nos mostrará a conversão dos estados no decorrer do tempo de um conglomerado para o outro, ou seja, de uma condição para outra. 
OPINIÃO PÚBLICA, Campinas, vol. 20, no 2, agosto, 2014, p.219-251

Quadro 2

Pertencimento dos estados nos agrupamentos: analfabetismo, anos de estudo e mortalidade infantil 1985 a 2011

\begin{tabular}{|c|c|c|c|}
\hline & Estado & $\begin{array}{c}\text { Agrupamento } \\
\text { ao qual } \\
\text { pertence }\end{array}$ & Ano(s) de pertencimento ao agrupamento \\
\hline \multirow[t]{14}{*}{ Norte } & \multirow[t]{2}{*}{ RO } & 1 & $19981999 \quad 200220032004200520062007200820092011$ \\
\hline & & 2 & $19851986198719881989199019921993199519961997 \quad 2001$ \\
\hline & \multirow[t]{2}{*}{ Acre } & 1 & $1998 \quad 20012002 \quad 2007200820092011$ \\
\hline & & 2 & $19851986198719881989199019921993199519961997 \quad 1999 \quad 2003200420052006$ \\
\hline & \multirow[t]{2}{*}{ AM } & 1 & 19992001200220032004200520062007200820092011 \\
\hline & & 2 & 198519861987198819891990199219931995199619971998 \\
\hline & \multirow[t]{2}{*}{ RR } & 1 & $19861987 \quad 1990 \quad 1993 \quad 1996199719981999 \quad 200220032004200520062007200820092011$ \\
\hline & & 2 & $\begin{array}{lllll}1985 & 19881989 & 1992 & 1995 & 2001\end{array}$ \\
\hline & \multirow[t]{2}{*}{ PA } & 1 & 20022007200820092011 \\
\hline & & 2 & 19851986198719881989199019921993199519961997199819992001 \\
\hline & \multirow[t]{2}{*}{ AP } & 1 & 1997199819992001200220032004200520062007200820092011 \\
\hline & & 2 & 1985198619871988198919901992199319951996 \\
\hline & \multirow[t]{2}{*}{ TO } & 1 & 200520062007200820092011 \\
\hline & & 2 & 19921993199519961997199819992001200220032004 \\
\hline \multirow[t]{20}{*}{ Nordeste } & \multirow[t]{3}{*}{ MA } & 1 & 2011 \\
\hline & & 2 & 19981999200120022003200420052006200720082009 \\
\hline & & 3 & 19851986198719881989199019921993199519961997 \\
\hline & \multirow[t]{2}{*}{$\mathrm{Pl}$} & 2 & 199819992001200220032004200520062007200820092011 \\
\hline & & 3 & 19851986198719881989199019921993199519961997 \\
\hline & \multirow[t]{3}{*}{$\mathrm{CE}$} & 1 & 200820092011 \\
\hline & & 2 & 19961997199819992001200220032004200520062007 \\
\hline & & 3 & 198519861987198819891990199219931995 \\
\hline & \multirow[t]{3}{*}{ RN e SE } & 1 & 2007200820092011 \\
\hline & & 2 & 199319951996199719981999200120022003200420052006 \\
\hline & & 3 & 1985198619871988198919901992 \\
\hline & \multirow[t]{3}{*}{ PB e BA } & 1 & 200820092011 \\
\hline & & 2 & 199519961997199819992001200220032004200520062007 \\
\hline & & 3 & 19851986198719881989199019921993 \\
\hline & \multirow[t]{3}{*}{ PE } & 1 & 20062007200820092011 \\
\hline & & 2 & 1995199619971998199920012002200320042005 \\
\hline & & 3 & 19851986198719881989199019921993 \\
\hline & \multirow[t]{3}{*}{$\mathrm{AL}$} & 1 & 2011 \\
\hline & & 2 & 1999200120022003200420052006200720082009 \\
\hline & & 3 & 198519861987198819891990199219931995199619971998 \\
\hline
\end{tabular}




\section{SÁTYRO, N. G. D. Padrões distintos de bem-estar no Brasil: uma análise temporal}

Quadro 2 (continuação)

Pertencimento dos estados nos agrupamentos: analfabetismo, anos de estudo e mortalidade infantil 1985 a 2011

\begin{tabular}{|c|c|c|c|}
\hline & Estado & $\begin{array}{l}\text { Agrupamento } \\
\text { ao qual } \\
\text { pertence }\end{array}$ & Ano(s) de pertencimento ao agrupamento \\
\hline \multirow{16}{*}{$\begin{array}{l}\text { Sudeste, } \\
\text { Sul e CO }\end{array}$} & \multirow{2}{*}{$\begin{array}{l}\text { MG e } \\
\text { GO }\end{array}$} & 1 & 200120022003200420052006200720082009 \\
\hline & & 2 & 1985198619871988198919901992199319951996199719981999 \\
\hline & \multirow{2}{*}{$\begin{array}{l}\text { ES e } \\
\text { MS }\end{array}$} & 1 & $2011 \quad 19981999200120022003200420052006200720082009$ \\
\hline & & 2 & 19851986198719881989199019921993199519961997 \\
\hline & \multirow{2}{*}{ RJ } & 1 & 201119901992199319951996199719981999200120022003200420052006200720082009 \\
\hline & & 2 & 19851986198719881989 \\
\hline & \multirow{2}{*}{$\begin{array}{l}\text { SP e } \\
\text { RS }\end{array}$} & 1 & 20111992199319951996199719981999200120022003200420052006200720082009 \\
\hline & & 2 & 198519861987198819891990 \\
\hline & \multirow{2}{*}{ PR } & 1 & $2011 \quad 199719981999200120022003200420052006200720082009$ \\
\hline & & 2 & 1985198619871988198919901992199319951996 \\
\hline & \multirow[t]{2}{*}{$\mathrm{SC}$} & 1 & 201119951996199719981999200120022003200420052006200720082009 \\
\hline & & 2 & 19851986198719881989199019921993 \\
\hline & \multirow{2}{*}{ MT } & 1 & 20022003200420052006200720082009 \\
\hline & & 2 & 19851986198719881989199019921993199519961997199819992001 \\
\hline & \multirow{2}{*}{ DF } & 1 & 2011 19861987198819891990199219931995199619971998199920012002 2003200420052006200720082009 \\
\hline & & 2 & 1985 \\
\hline
\end{tabular}

Esse cenário nos mostra ainda que o norte se parece mais com a parte sul do país do que com o nordeste, região com a qual é sempre comparado no senso comum. As médias dos indicadores do norte colocaram-no no $2^{\circ}$ conglomerado no início com momentos distintos entre os estados de passagem para o $1^{\circ}$ conglomerado. Já os estados nordestinos passaram a década de 1980 em um $3^{\circ}$ conglomerado onde o acesso aos serviços básicos era baixo; a passagem para o $2^{\circ}$ conglomerado se deu em tempos distintos em cada estado, sugerindo o peso do legado em cada caso. Os extremos como Maranhão e Alagoas só conseguem pertencer ao $1^{\circ}$ conglomerado no último ano da série, enquanto o Piauí ainda não saiu do $2^{\circ}$.

As tendências não se alteram muito quando inserimos o grau de informalidade do mercado de trabalho como um dos componentes dos conglomerados; são 3 (três) conglomerados. A análise se inicia no ano de 1993 e vai até 2009.

Primeiro, todos os estados do nordeste passam do $1^{\circ}$ conglomerado (de proteção social menos institucionalizada, mais frágil) para o $2^{\circ}$ conglomerado (estágio intermediário). Entretanto, Maranhão e Piauí só conseguem essa melhora nos 2 e 3 últimos anos da série, respectivamente. Os estados do norte do país não apresentam homogeneidade de trajetórias. Acre, Pará e Tocantins se assemelham aos estados nordestinos, enquanto Rondônia, Amazonas e Roraima estão mais próximos do comportamento de Minas Gerais, Espírito Santo, Paraná, Mato Grosso, Mato Grosso do Sul e Goiás que, durante o período analisado, passam do $2^{\circ}$ conglomerado para o $3^{\circ}$. Esse $3^{\circ}$ é composto pelos estados que possuem os melhores valores relativos dentro do conjunto: Rio de Janeiro, São Paulo, Santa Catarina, Rio 


\section{OPINIÃO PÚBLICA, Campinas, vol. 20, no 2, agosto, 2014, p.219-251}

Grande do Sul, Goiás e Distrito Federal pertencem ao conglomerado 3 em toda a série temporal. Amapá passa do $2^{\circ}$ para o $3^{\circ}$, mas em 2009 cai de posição novamente.

Ou seja, também ao considerar a informalidade os estados nordestinos apresentam uma realidade de proteção social muito distinta do sul e do sudeste do país. Isso corrobora os achados de Ibarra (2007) que mostra a tardia inflexão no país do indicador de informalidade e nossos dados mostram o enorme desvio-padrão com o qual estamos lidando quando falamos dessa inflexão nacional.

\section{Considerações Finais}

Neste artigo, fizemos um exercício que permite distinguir inicialmente a existência de dois padrões de educação e de saúde, ou seja, de formação de competências: o padrão sul-sudeste com altos níveis de educação formal, baixos níveis de analfabetismo, e baixos índices de mortalidade infantil e o padrão nordeste com baixos níveis de ensino, alto nível de analfabetismo escolar e altos índices de mortalidade infantil. Essa heterogeneidade se traduz em padrões distintos de segurança social: o padrão sul-sudeste com altos níveis de segurança social, com proteção advinda do emprego e baixos índices de pobreza e o padrão dos demais estados com altos índices de informalidade, ou seja, de baixo nível de proteção advinda de emprego formal. E isso nos permite inferir que havia (e ainda há) um acesso diferenciado à cidadania porque, no conjunto, estamos falando de um padrão de capital humano em níveis muito distintos.

Os resultados sugerem que o crescimento econômico e a melhoria do mercado de trabalho vistos a partir de meados da década de 1990 bem como as melhorias das condições sociais tiveram um efeito muito diferente sobre o desenvolvimento dos níveis de bem-estar social nos estados de acordo com a linha de base ali encontrada, entendida aqui como resultado das políticas prévias. Estados que ao final das três décadas se apresentam ainda com os resultados piores em seus indicadores foram originalmente aqueles que partiram de níveis de acesso a serviços básicos muito mais baixos. Isso sugere a importância do conceito de rota dependente de trajetória para explicar como no Brasil na última década tem havido uma diminuição das distâncias entre os diferentes mundos de bem-estar existentes há 30 anos, mas que os ritmos são muito distintos.

Até aqui apenas obviedades. Entretanto, o importante é ressaltar que as distâncias entre os dois mundos de bem-estar só mudam a sua tendência para um movimento forte de diminuição das distâncias a partir dos anos 2000. Um artigo de natureza descritiva como este não permite grandes inferências, mas sugere a importância da mudança das regras do jogo quando a saúde passa a ser um direito universal, quando houve a obrigatoriedade da educação a crianças de 7 a 14 anos (com posterior espraiamento dessa faixa etária a partir do governo Lula), quando a assistência social foi reconhecida como política pública gerando uma série de programas e políticas protetivas. Os achados aqui sugerem que, para além das boas consequências do crescimento econômico, foi imprescindível a inserção de solidariedade no sistema e a mudança paradigmática no sistema de proteção social brasileiro. Ao que parece, a estabilização econômica iniciada a partir do primeiro governo Fernando Henrique Cardoso, de um lado, e a ampliação dos direitos sociais por meio do acesso de boa parte população antes excluída, por outro lado, levaram ao início de uma nova fase em nossa história. Mas, isso, para ser afirmado peremptoriamente, merece estudo de natureza mais explicativa. 


\section{SÁTYRO, N. G. D. Padrões distintos de bem-estar no Brasil: uma análise temporal}

Em síntese, no período estudado, assistimos a uma reconfiguração do nosso EBES no que tange ao seu poder de estratificação social. Além disso, ao que parece, as rotas anteriores fazem com que ainda tenhamos um cenário com acessos diferenciados à cidadania. A análise aqui empreendida mostra que estamos no caminho certo para a quebra de um "equilíbrio Pareto-inferior", onde uma grande desigualdade educacional gera uma desigualdade de acesso ao mercado de trabalho, que, por sua vez, perpetua a desigualdade de cidadania. Assim, não há como não terminar com uma citação de Ferreira que disse que estamos diante de um cenário em que

\footnotetext{
"a luta de classes não se dá nos pátios das montadoras de automóveis do ABC paulista, como muitos pensavam, e sim no desenho de nosso sistema educacional, nas diferenças entre a prioridade do financiamento da educação pública primária e secundária e a de outros itens do orçamento estatal, e, por conseguinte, na diferença entre o que se aprende nas melhores escolas particulares das grandes metrópoles do sudeste e nas escolas públicas de suas periferias, ou da caatinga do Piauí, ou nas margens dos igarapés amazonenses" (FERREIRA, 2000, p.144).
}

Por fim, cabe enfatizar que essas são hipóteses para futuras pesquisas pois a trajetória aqui analisada sugere que as determinações constitucionais sozinhas podem não induzir a ação em determinados contextos, mas em países marcados por alto grau de heterogeneidade, a determinação constitucional de reestruturação das estruturas das políticas sociais bem como a adoção de diretrizes de políticas nacionais são imprescindíveis para a construção de uma cidadania plena e universal. No âmbito da saúde e da educação os dados aqui apresentados sugerem o efeito dessas determinações no tempo.

\section{Referências Bibliográficas}

AmentA, E; Skocpol, T. "States and social policies". Annual Review of Sociology, vol.12, p.131.57, 1986.

ARRETCHE. M. "Emergência e desenvolvimento do Welfare State: teorias explicativas". BIB - Boletim Informativo Bibliográfico de Ciências Sociais, n³9, p.3-40, 1995.

Aureliano, L.; DraiBe, S.M. "A especificidade do 'Welfare State' brasileiro". In: Economia e desenvolvimento: reflexões sobre a natureza do bem-estar, vol.1. Brasília: MPAS/ CEPAL, 1989.

BALTAR, P. "Estrutura ocupacional regional nos anos 90" In: X// Encontro Nacional de Estudos Populacionais. ABEP, Caxambu, 2000.

Barros, R.P.; Corseuil, C. H.; Leite, P. G. Mercado de trabalho e pobreza no Brasil. In: HenriQues, R. (org.). Desigualdade e pobreza no Brasil. Rio de Janeiro: IPEA, 2000.

.; Foguel, M. N.; UlySSEA, G. (org.). Desigualdade de Renda no Brasil: Uma Análise da Queda Recente. Brasília: IPEA, vol. 2. 2007.

CASTLES, F.G. The future of the welfare state: crisis myths and crisis realities. Oxford: Oxford Univ. Press, 2004.

"What welfare states do: a disaggregated expenditure approach". Journal of Social Policy, n 38 (part.1), p.45.62, 2008

CAStro, J.A.; CARdoso JR. Políticas sociais no Brasil: gastos do governo federal de 1988 a 2002. In: JACcoud, L. (org.). Questão social e políticas sociais no Brasil contemporâneo. Brasília: IPEA, 2005. 


\section{OPINIÃO PÚBLICA, Campinas, vol. 20, no 2, agosto, 2014, p.219-251}

CLASEN, J. Reforming European welfare states: Germany and the United Kingdom compared. Oxford: Oxford Univ. Press. 2005.

.; SIEgEL, N. A. Comparative welfare state analysis and the 'dependent variable problem'. In: CLASEN, J.; SIEGEL, N. A. Investigating welfare state change. The 'dependent variable problem' in comparative analysis. Cheltenham: Edward Elgar, 2007.

DedeccA, C.S. "Notas sobre a Evolução do Mercado de Trabalho no Brasil". Revista de Economia Política, vol. 25, n¹(97), p. 94-111, jan.-mar. 2005.

DralBe, S. M. "Welfare State no Brasil: Características e Perspectivas", Cadernos de Pesquisa, n8, NEPP/Unicamp, Campinas. 1993.

"América Latina: o Sistema de Proteção Social na Década da Crise e das Reformas", Cadernos de Pesquisa. n³0, NEPP/Unicamp, Campinas, 1995.

“A política social do governo FHC e o sistema de proteção social”. Tempo Social, São Paulo, vol.15, n², 2003.

"Brasil 1980-2000: Proteção e Insegurança Sociais em Tempos Difíceis", Cadernos de Pesquisa, n 65, NEPP/Unicamp, Campinas, 2005.

Estado de bem-estar, desenvolvimento econômico e cidadania: algumas lições da literatura contemporânea. In: hochman, G.; Arretche, M.; Marques, E. (orgs.). Políticas Públicas no Brasil. Rio de Janeiro: Ed. FioCruz, 2007.

.; RIESCO, M. "Estado de bienestar, desarollo econômico y ciudadania: algunas lecciones de la literatura contemporânea". Estudios y perspectiva, 55, CEPAL, 2006.

Esping-Andersen, G. Politics against markets - the Social Democratic Road to Power. Princeton: Princeton University, 1985a.

"Power and Distributional Regimes". Politics \& Society, n¹4, vol.2, p.223-56, 1985b.

The three worlds of welfare capitalism. Cambridge: Polity Press, 1990.

“As Três Economias Políticas do Welfare State". Lua Nova, n² 24, p.85.116, set. 1991.

Social foundations of postindustrial economies. Princeton: Princeton University, 1999.

Evans, P.B.; Rueschmeyer, D.; Skocpol, T. Bringing the State Back. In: Cambridge: Cambridge University, 1985.

FERREIRA, F.H.G. Os Determinantes da Desigualdade de Renda no Brasil: Luta de Classes ou Heterogeneidade Educacional. In: HenRIQUeS, R. (org.). Desigualdade e Pobreza no Brasil. Rio de Janeiro: IPEA, 2000.

Fishlow, A. "Brazilian size distribution of income". American Economic Review, vol. 62, n² 2, p.391.402, mai. 1972.

FLEURY, S. A montagem do padrão de seguridade social na América Latina. In: Estado sem cidadãos: seguridade social na América Latina. Editora: Editora Fiocruz, 1994.

HUber, E.; StePhens, J.D. Development and crisis of the welfare state: parties and policies in global markets. Chicago: University of Chicago Press. 2001.

IBARRA, A. "Pobreza, Distribuição de Renda e Mercado de Trabalho: 1990-2006". Mimeo, 2007.

IMmERGut, E.M. As regras do jogo: a lógica da política de saúde na França, na Suíça e na Suécia. Nova York: Cambridge University Press, 1992.

IPEA. Boletim de políticas sociais: análise e acompanhamento, vol. 17, Brasília: IPEA, 2009.

KoRPI. W. The democratic class struggle. London: Routledge; Kegan, 1983.

Marshall, T. H. Cidadania, Classe Social e Status. Rio de Janeiro: Zahar, 1967.

MONTALI, L. "Rearranjos familiares de inserção, precarização do trabalho e emprobrecimento". Revista Brasileira Est. Pop, Campinas, vol.21, n² , p.195.216, jul-dez. 2004.

MooRI, R.G; MARCONDES, R.C.; ÁvILA, R.T. "A análise de agrupamentos como instrumento de apoio à melhoria da qualidade dos serviços aos clientes". Revista de Administração Contemporânea, vol. 6, n 1, p. 63.84, 2002. 


\section{SÁTYRO, N. G. D. Padrões distintos de bem-estar no Brasil: uma análise temporal}

NoRTH, D. Five Propositions about Institutional Change. In: KNIGHT, J.; SENED, I. (eds.). Explaining Social Institutions. Ann Arbor: The University of Michigan Press, 1995.

Pierson, P. "Increasing Returns, Path Dependence, and the Study of Politics". American Political Science Review, vol.94, $\mathrm{n}^{\circ}$ 2, p.251-267. 2000.

"The new politics of the welfare state". World Politics, p.143-179, 2001.

Resende, G.M.; Mata, D.; Carvalho, A. X. Y . Crescimento Pró-pobre e Distribuição de Renda das Capitais dos Estados Brasileiros. In: CARvalho, A. et al (org.). Ensaios de Economia Regional e Urbano. Brasília: IPEA, p. 21.46, 2007.

SABoIA, J.L.M. "Transformações no mercado de trabalho no Brasil durante a crise: 1980-1983". Revista de Economia Política, vol 6, jul-set. 1986.

SANTOS, W.G. Cidadania e Justiça: a política social na ordem brasileira. Rio de Janeiro: Editora Campus Ltda, 1979.

SÁTYRo, N.G.D. Proteção social no Brasil (verbete de dicionário). Rio de Janeiro: FGV, 2010.

"Política Estadual e Desigualdade: Por que alguns estados redistribuem mais do que outros?". Dados, vol.56, p.497.530, 2013.

.; CUNHA, E.S.M. "The pathy of Brazilian social assistance policy post - 1988: the significance of institutions and ideas". Brazilian Political Science Review, vol.8, 2014

SKOCPOL, T. Bringing the State Back in: strategies of analysis in current research. In: EVANS, P.B.; RUESCHEMEYER, D.; SkOCPOL, T. (eds.). Bringing the State Back in. Cambridge: Cambridge University, 1985.

Protecting Soldiers and Mothers: the Political Origins of Social Policy in the United States. Cambridge, MA: The Belknap Press of Harvard University Press; 1992.

SouZA, C. "Regiões metropolitanas: condicionantes do regime político". Lua Nova, n 59, 2003.

Titmuss, R. M. What is social policy? In: Abel-Smith, B.; TItmuss, K. (eds.). Social Policy. London: George Allen and Unwin, p. 23.33, 1974.

WeIr, M.; Orloff, A.; Skocpol, T. (eds.). The Political Formation of the U.S. Welfare State, Princeton: Princeton University Press, 1988.

Natália Guimarães Duarte Sátyro·nsatyro@gmail.com

Submetido à publicação em setembro de 2012 . Versão final aprovada em janeiro de 2014. 